\title{
Disruption of Experience-Dependent Synaptic Modifications in Striate Cortex by Infusion of an NMDA Receptor Antagonist
}

\author{
Mark F. Bear, ${ }^{2}$ Andreas Kleinschmidt, ${ }^{1}$ Qiang Gu, ${ }^{1}$ and Wolf Singer ${ }^{1}$ \\ 'Max Planck Institut für Hirnforschung, 6000 Frankfurt 71, Federal Republic of Germany, and ${ }^{2} T h e$ Center for Neural \\ Science, Brown University, Providence, Rhode Island 02912
}

To assess the possibility that NMDA receptors play a special role in visual cortical plasticity, the selective antagonist 2-amino-5-phosphonovaleric acid (APV) was continuously infused into the striate cortex of kittens as the visual environment was manipulated during the critical period. The cortex was studied using single-unit recording from sites between 3 and $6 \mathrm{~mm}$ from the infusion cannulae. One week of D,L-APV infusion coincident with monocular deprivation or "reverse suture" produced a concentration-dependent increase in the percentage of neurons that (1) lacked normal orientation selectivity and (2) were responsive to stimulation of the deprived eye. These effects outlasted the presence of the drug in the tissue. APV treatment also prevented the acquisition of selectivity and visual responsiveness that normally results from monocular visual experience after darkrearing. Lasting effects of chronic APV infusion were not observed in adult striate cortex.

The effects of APV on kitten striate cortex depended on the presence of the $D$ stereoisomer as infusion of L-APV was without effect. Estimates of extracellular concentration using ${ }^{3} \mathrm{H}$-APV indicated that significant effects could be obtained with concentrations as low as $20 \mu \mathrm{M}$ D,L-APV. Recordings from units during infusion indicated that visual responses were reduced by APV. Nonetheless, a normal percentage of visually responsive neurons was found at sites $\geq 3 \mathrm{~mm}$ from the infusion cannula. There was no evidence that chronic APV infusion affected the sampling frequency of recorded neurons or disrupted cytoarchitecture at the sites further than $3 \mathrm{~mm}$ from the infusion cannula. Taken together, the data indicate that the effects of APV on kitten striate cortex are likely due specifically to the blockade of NMDA receptors. These data are considered in relation to several hypotheses concerning the role of NMDA receptors in the experience-dependent development of striate cortex.

The developing visual cortex presents a considerable challenge to students of experience-dependent synapse modification. The characteristic physiological response properties of neurons in the mature striate cortex - selectivity for the orientation of a bar

\footnotetext{
Received Mar. 3, 1989; revised Aug. 14, 1989; accepted Oct. 4, 1989.

This work was supported in part by the U.S. Office of Naval Research, the National Eye Institute, and the Alfred P. Sloan Foundation. We wish to thank Helga Duckstein, Christa Ziegler, Alexa Franke, and Howard Colman for their valuable technical assistance, and Jim McIlwain and Eugene Clothiaux for critically reading the manuscript.

Correspondence should be addressed to Mark F. Bear, Center for Neural Science, Brown University, P.O. Box 1953, Providence, RI 02912.

Copyright (C) 1990 Society for Neuroscience $0270-6474 / 90 / 030909-17 \$ 02.00 / 0$
}

of light and responsiveness to stimulation of either eye-both depend critically upon visual experience during early postnatal development. Accordingly, these properties may be modified by experimental manipulations of the visual environment during a postnatal period, which, in the cat, extends from 3 weeks to 3 months of age (Hubel and Wiesel, 1970). For example, prolonged deprivation of visual patterns during the sensitive period by patching both eyes or by rearing animals in complete darkness nearly eliminates orientation selectivity and reduces visual responsiveness (Sherman and Spear, 1982; Frégnac and Imbert, 1984). Binocular connections are modified after even very brief periods (1-2 days) of monocular deprivation (MD) as well as by optical misalignment of the 2 eyes (Wiesel and Hubel, 1965). Can a single mechanism account for these varied experience-dependent synaptic modifications? Theoretical analyses over the past 2 decades have suggested that this could be the case, if synapses in the visual cortex modified according to variations upon a simple rule first proposed by Hebb in 1949 (Cooper, 1973; Stent, 1973; von der Malsburg, 1973; Bienenstock et al., 1982; Linsker, 1986). According to its most general form, this hypothesis states that only those connections which participate in the activation of their postsynaptic target are retained and consolidated during development; ineffective inputs are lost.

Modification of binocular connections offer a good example of how Hebb's rule could operate in the visual cortex. When the eyes are in optical alignment, the input signals arising from homotypic points in the 2 retinae impinge upon their cortical targets at the same time. The summation of this convergent input depolarizes the target neuron above some threshold and, according to Hebb's rule, these connections are strengthened. When the signals from the 2 eyes become asynchronous, such as after artificially induced squint (strabismus) or after patching one eye, the dominant input (that most effective in activating the target) is retained, while the nondominant input (that less effective in activating the neuron) is lost. Experimental tests of this hypothesis have involved attempts to manipulate the responses of cortical neurons to input signals as one eye is deprived of vision. For example, in one early series of experiments, kittens were presented with visual stimuli that created an imbalance in the presynaptic geniculocortical fiber activity from the 2 eyes but that were relatively ineffective in driving cortical neurons. Under these conditions, little shift in cortical ocular dominance towards the more active eye was observed (Singer et al., 1977; Rauschecker and Singer, 1979, 1982). More recently, Reiter and Stryker (1988) reported that active inputs failed to consolidate when postsynaptic activity was inhibited by infusing the GABA receptor agonist muscimol into the cortex. In an effort to in- 
crease the probability that the activity conveyed along deprived eye afferents correlated with cortical activity, Ramoa et al. (1989) disinhibited the cortex by infusing low concentrations of the $\mathrm{GABA}_{\mathrm{A}}$ receptor antagonist bicuculline and found that the deprived eye inputs were retained in area 17 . Finally, both Frégnac et al. (1988) and Greuel et al. (1988) found in acute preparations that synaptic effectiveness could be changed by pairing retinal stimulation with the ionophoretic application of substances which alter the postsynaptic response. Together, these results support the hypothesis that the coincidence of pre-and post-synaptic activity is a crucial variable for the maturation of synaptic strength during early postnatal development.

A question of extraordinary interest concerns the neural mechanisms which subserve "Hebbian" modification in the cerebral cortex. One strong candidate is the NMDA receptor mechanism (reviewed by Bear et al., 1987; Brown et al., 1989). NMDA receptors are thought to coexist postsynaptically with other types of excitatory amino acid (EAA) receptors (Foster and Fagg, 1985). Together, both NMDA and non-NMDA type EAA receptors mediate excitatory synaptic transmission in the kitten striate cortex (Tsumoto et al., 1986). The ionic conductances activated by non-NMDA receptors at any instant depend only on the input activity and are independent of the postsynaptic membrane potential. However, the ionic channels linked to NMDA receptors are blocked with $\mathrm{Mg}^{2+}$ at the resting potential and become effective only upon membrane depolarization (Nowak et al., 1984; Mayer and Westbrook, 1987). Another distinctive feature of the NMDA receptor channel is that it will conduct calcium ions (Dingledine, 1983; MacDermott et al., 1986). Hence the passage of $\mathrm{Ca}^{2+}$ through the NMDA channel could specifically signal when pre- and postsynaptic elements are concurrently active. The type of synaptic modification envisaged by $\mathrm{Hebb}$ could be explained if this $\mathrm{Ca}^{2+}$ signal were to lead to lasting biochemical or structural changes that increased synaptic efficacy.

The first indication that NMDA receptors might play a special role in regulating synaptic strength came from work on longterm potentiation (LTP) in the hippocampus. High-frequency electrical stimulation of several excitatory afferent pathways leads to a lasting increase in the effectiveness of the stimulated synapses both in vivo and in vitro (Bliss and Lømo, 1973; Andersen, 1987). Induction of LTP with electrical stimulation requires the coactivation of converging excitatory afferents (McNaughton et al., 1978) and the depolarization of the postsynaptic target (Kelso et al., 1986). A major advance came with the introduction of the selective NMDA receptor antagonist 2-amino-5-phosphonovaleric acid (APV; Watkins and Evans, 1981). Collingridge et al. (1983) and Harris et al. (1984) found that APV application to hippocampal slices in vitro reliably blocked the induction of LTP in the CA1 region, even though it had little effect on the synaptic response to test stimuli. A current working hypothesis for the mechanism of ITP induction is that the synchronous tetanic activation of converging afferents depolarizes the target dendrite beyond the threshold for $\mathrm{Ca}^{2+}$ entry through gates linked to the NMDA receptor (Wigström and Gustafsson, 1985). Elevated dendritic $\mathrm{Ca}^{2+}$ is thought to trigger the intracellular changes that lead to enhanced synaptic efficacy (Lynch et al., 1983; Lynch and Baudry, 1984; Malenka et al., 1988).

Recent work has shown that synaptic potentiation also occurs in preparations of striate cortex in vitro (Artola and Singer, 1987; Berry et al., 1988; Komatsu et al., 1988; Perkins and Teyler,
1988) and that this depends on NMDA receptor activation both in rats (Artola and Singer, 1987; Kimura et al., 1988) and in kittens during the critical period (Conors and Bear, 1988). These findings support the idea that NMDA receptors might play an important role in the modification of synaptic strength in the visual cortex during postnatal development. However, direct tests of this hypothesis require that NMDA receptors in the visual cortex be blocked in vivo at the same time that synaptic modifications are induced to occur. In this paper we describe experiments in which APV was continuously microperfused into kitten striate cortex as the visual environment was manipulated in various ways. Our results show that APV treatment disrupts the process of synaptic modification in a concentration-dependent manner. These findings support the hypothesis that NMDA receptors play a central role in the modification of visual cortical organization by sensory experience. Some of the data presented here have been reported previously in brief form (Kleinschmidt et al., 1987; Gu et al., 1989).

\section{Materials and Methods}

Experimental design. The object of our experiments was to block NMDA receptors in area 17 as visual experience was manipulated during the critical period. Miniature osmotic pumps (ALZA 2001) were used to deliver D,L-APV dissolved in sterile saline to striate cortex via a chronically implanted stainless steel cannula fashioned from a 27 gauge hypodermic needle. The rate of infusion was $1 \mu \mathrm{l} / \mathrm{hr}$, and the duration in most cases was $7 \mathrm{~d}$. After this treatment, the striate cortex was assayed for deficits in experience-dependent development using standard physiological recording methods (Fig. 1).

There are a number of limitations to this minipump strategy. The most severe are that (1) the chronic implantation of cannulae and continual infusion characteristically lead to cortical lesions that can measure $1-2 \mathrm{~mm}$ in diameter (see Paradiso et al., 1983), and (2) the concentration of an infused drug falls off exponentially with increasing distance away from the cannula (see Kasamatsu et al., 1981). Thus, the region of cortex used for physiological recording must be far enough away from the infusion site to avoid damaged tissue, yet be close enough to have been treated with a concentration of APV which is adequate to block NMDA receptors. We usually studied a sample area that extended from 3-6 $\mathrm{mm}$ from the infusion cannula (Fig. 1). In order to achieve a steadystate extracellular concentration of APV of approximately 20-200 $\mu \mathrm{M}$ in this sample area (the concentration range which reliably and selectively blocks induction of LTP in hippocampus and neocortex in vitro), we chose an APV concentration in the minipump of 5-50 mM (yielding an infusion rate of $5-50 \mathrm{nmol} / \mathrm{hr}$ ). Previous measurements of the spatial distribution of several drugs infused into the striate cortex via ALZA 2001 minipumps had shown a 500 -fold dilution by $3 \mathrm{~mm}$ (see Kasamatsu et al., 1981). Our own measurements of ${ }^{3} \mathrm{H}-\mathrm{D}, \mathrm{L}-\mathrm{APV}$ revealed that the concentration at $3-6 \mathrm{~mm}$ is approximately $200 \mu \mathrm{M}$ after $4 \mathrm{~d}$ of infusion at $50 \mathrm{nmol} / \mathrm{hr}$ (see Results). Although APV is generally considered to be a potent and highly selective NMDA receptor antagonist (Watkins and Evans, 1981), we are obliged to acknowledge at the outset that it is possible that our results could be explained by an unknown action of D-APV that is independent of its effects at NMDA receptors.

An additional potentially confounding variable with minipump experiments is that drugs may not be stable in solution at $38^{\circ} \mathrm{C}$ for extended periods of time (see Haycock and Bear, 1984). We addressed this question by studying the effectiveness of APV which had been maintained at $38^{\circ} \mathrm{C}$ for $7 \mathrm{~d}$ in blocking responses in vitro that are dependent on NMDA receptors (Artola and Singer, 1987). The results of this test indicated that APV remains a potent and selective NMDA receptor antagonist throughout the period of minipump infusion.

Minipump implantation procedure. Kittens between 3 and 5 weeks of age were anesthetized with a ketamine-xylazine mixture i.m. and placed in a stereotaxic frame. Minipumps, connected with polyethylene tubing to stainless steel cannulae, were implanted bilaterally beneath the skin of the neck. In most cases, one pump was filled with D,L-APV dissolved in sterile saline and the other pump was filled with saline alone. In this way, the saline-infused hemispheres served as internal controls. In 2 additional control experiments, we used the pharmacologically inactive L stereoisomer of APV. 
Small vurr holes were made in the skull approximately $5 \mathrm{~mm}$ posterior to the interaural line and lateral $\sim 1.5 \mathrm{~mm}$ from the midline. Through these holes, the 27 gauge bevelled cannulae were lowered into the cortex with the aid of a micromanipulator. The needle tips were inserted 2 $\mathrm{mm}$ below the dura and secured to the skull with dental cement. To ensure proper adhesion, the surface of the skull was wiped with ether prior to applying the cement. After the dental acrylic had hardened, the scalp was sutured closed. When the experiment called for simultaneous $\mathrm{MD}$ and APV treatment (Fig. $1, A-C, E, F$ ), the margins of the right eyelid were then trimmed and sutured closed. The animals were monitored closely over the subsequent week(s), and local or systemic antibiotics were given if necessary.

Physiological recordings. In order to assay for changes in the physiological organization of striate cortex, the animals were anesthetized, paralyzed, and prepared for routine physiological recording from neurons in area 17. In most cases (Fig. $1, A-D, F$ ), the cannulae and minipumps were removed prior to recording. A detailed description of the preparation may be found elsewhere (Greuel et al., 1987). During the recording session, the kittens were artificially respired on $70 \%$ nitrous oxide and $30 \%$ oxygen, and received a continuous intravenous infusion of Nembutal $(2 \mathrm{mg} / \mathrm{kg} / \mathrm{hr})$ and Imbretil $(1 \mathrm{mg} / \mathrm{kg} / \mathrm{hr})$ in Ringer's solution. The EEG, ECG, and expired $\mathrm{CO}_{2}$ were monitored continuously, and body temperature maintained at $37.5^{\circ} \mathrm{C}$. To compensate for the loss of fluid, the kittens were infused with a glucose-Ringer solution through an orally inserted gastric catheter.

In most cases (Fig. 1, $A-D, F$ ), single units were recorded from area 17 with micropipettes filled with $1.5 \mathrm{M}$ potassium citrate (impedance $\sim 15 \mathrm{M} \Omega$ ). Several long electrode penetrations, angled obliquely, were made down the medial bank of the postlateral gyrus through the area centralis representation, usually 3-6 mm anterior to the position of the infusion cannula. Receptive fields were analyzed by projecting onto a tangent screen hand-held light stimuli consisting of slits whose length, width, and orientation could be varied.

Classification of recorded units and data analysis. Each unit encountered along an electrode track was carefully classified, using strict criteria, for ocular dominance (OD), orientation selectivity (SEL) and response quality $(R Q)$. Neurons assigned to OD categories 1 and 5 were activated by either the right or left eyes, respectively, but not both. Neurons assigned to OD category 3 were activated equally strongly by stimulation of either eye. Cells in OD categories 2 and 4 were binocular, but their responses were clearly dominated by either the right or left eyes, respectively.

Orientation selectivity was assessed by passing light bars of various orientations across the receptive field. Units that responded to all orientations, without any clear preference, were assigned to SEL category 1. Neurons in SEL category 2 also responded to all orientations, but certain orientations yielded responses that were clearly greater $(\geq 2 \times)$ than others. Cells for which certain orientations produced no response were grouped in SEL category 3. Unoriented visual stimuli were also used to distinguish orientation from direction selectivity.

$\mathrm{RQ}$ is a subjective assessment of the vigor and reliability of neuronal responses to light and has proved to be a useful measure in studies of developmental plasticity. Neurons in RQ category 3 respond reliably and briskly in every trial. Neurons in RQ category 2 show some response variability from trial to trial, but their receptive fields are still easily defined with hand mapping. Cells assigned to RQ category 1 respond only sluggishly to light, do not respond in every trial, and often require computer averaging to accurately map their receptive fields. In addition, neurons for which no receptive field can be identified are recorded as "unclassifiable," or U.

For each hemisphere in which $\geq 20$ units were recorded, the OD, SEL, and $R Q$ data were used to calculate quantitative indices that were utilized for statistical comparisons between experimental groups. The Open Eye Dominance (OED) index is the number of cells in OD category 5 plus $0.5 \times$ the number of cells in OD category 4 divided by the total number of classifiable cells. The Binocularity (B) index is the number of cells in OD categories 2-4 divided by the total number of classifiable neurons. The Orientation Selectivity and Response Quality indices are the number of cells in SEL and RQ category 3 , respectively, divided by the total number of classifiable units (the RQ ratings of responses to dominant eye stimulation are used to calculate the RQ index). A 1-way analysis of variance was used to evaluate the differences between groups. $p<0.05$ was considered a significant difference.

Tests of visual responsiveness during $A P V$ infusion. In one experimental series (Fig. $1 E$ ), we set out to determine the overt effects of APV on visual responsiveness as it is infused by minipump at $50 \mathrm{nmol} / \mathrm{hr}$. The object was to map the percentage of visually responsive cells as a function of distance away from the infusion cannula. To facilitate mapping, in most of these experiments we used low-impedance platinumiridium electrodes which generally sampled multiunit activity. Glued to the electrode was a 7-barreled microionophoresis pipette which allowed us to activate otherwise silent neurons with glutamate or NMDA ( 0.1 and $0.05 \mathrm{M}$, respectively, $\mathrm{pH} \sim 8$ ). A balance barrel contained saline. Drugs were retained with $+5 \mathrm{nA}$ of current and passed with currents ranging from -5 to $-200 \mathrm{nA}$. In these mapping experiments, data were collected at $100 \mu \mathrm{m}$ intervals along each electrode track. Several $2-\mathrm{mm}$ long electrode penetrations were made at varying distances from the infusion cannula.

Estimates of tissue drug concentrations using ${ }^{3} \mathrm{H}-A P V$. In an effort to determine the spatial distribution of the drug during infusion, pumps were filled with $50 \mathrm{~mm}$ APV containing $2.5 \mu \mathrm{Ci}$ of ${ }^{3} \mathrm{H}$-APV (Tocris Neuramin). After $4 \mathrm{~d}$ of infusion, the animal was deeply anesthetized, the brain exposed, and the striate cortex frozen in situ with liquid nitrogen. A block of area 17 was allowed to thaw slightly and $500-\mu \mathrm{m}$ thick slices were rapidly prepared using a McIlwain tissue chopper. Each slice was put in $1 \mathrm{ml}$ of water and sonicated. Half of the sonicate was analyzed for protein content using the method of Bradford (1976). The protein content of each slice was used to calculate the tissue wet weight Scintiverse, $4 \mathrm{ml}$, was added to the remaining $0.5 \mathrm{ml}$ of sonicate, and the radioactivity measured using a liquid scintillation counter. Knowing the specific activity of the radioactive APV solution, it was then possible to calculate the nmol APV/mg tissue at each distance away from the cannula.

A fraction of the ${ }^{3} \mathrm{H}$-APV measured in the tissue is free in the extracellular space, a fraction is bound specifically to NMDA receptors, and a fraction is bound unspecifically to membranes. In addition, it is possible that some ${ }^{3} \mathrm{H}$ is sequestered intracellularly. In order to estimate the extracellular concentration of APV from our measures of nmol APV/ $\mathrm{mg}$, we devised an experiment in which slices of visual cortex were maintained in vitro at $37^{\circ} \mathrm{C}$ in continuously oxygenated artificial cerebrospinal fluid (120 mM NaCl, $5 \mathrm{~mm} \mathrm{KCl}, 1 \mathrm{~mm} \mathrm{MgCl}, 1 \mathrm{~mm} \mathrm{CaCl}$, $10 \mathrm{~mm}$ D-glucose, $20 \mathrm{~mm}$ HEPES adjusted to $\mathrm{pH} 7.40$ at $37^{\circ} \mathrm{C}$ with $\mathrm{NaOH}$ ) containing known concentrations of ${ }^{3} \mathrm{H}-\mathrm{APV}$. After various times, the slices were rapidly filtered to remove the incubation medium and prepared as described above to measure the nmol APV/mg tissue. This allowed us to construct a standard curve from which we were able to calculate the extracellular concentration of APV from our measures of tissue APV content.

Histology. At the end of each physiological recording session, the animal was given an overdose of Nembutal and perfused through the ascending aorta with $4 \%$ formalin. The brain was removed, cryoprotected, and sectioned on a freezing microtome at $50 \mu \mathrm{m}$ in either the coronal or parasagittal planes. These sections were mounted onto microscope slides and stained for Nissl substance with cresyl violet acetate. Most cases were examined to assess the extent of the lesion caused by the infusion cannulae and to recover electrode tracks when possible.

\section{Results}

Effects of monocular deprivation on striate cortex infused with $A P V$

The initial test of the effect of NMDA receptor blockade on experience-dependent cortical modifications was to see if APV infusion interfered with the ocular dominance shift that normally results from 1 week of MD during the critical period. Normally reared kittens were monocularly deprived by lid suture and implanted with minipumps that were filled with 5 or $50 \mathrm{~mm}$ D,L-APV (Fig. 1, $A, B$ ). After 1 week, the pumps were removed and the striate cortex was assayed for changes in its physiological organization.

The results of 5 cases in which the minipumps contained 5 mм APV (Table 1, experiment A) are summarized in Figure 2. In a zone of cortex extending from 2 to $6 \mathrm{~mm}$ from the site of APV infusion, we found that many neurons displayed response properties that are expected from a monocularly deprived, but otherwise normal, kitten: tight orientation tuning and ocular 


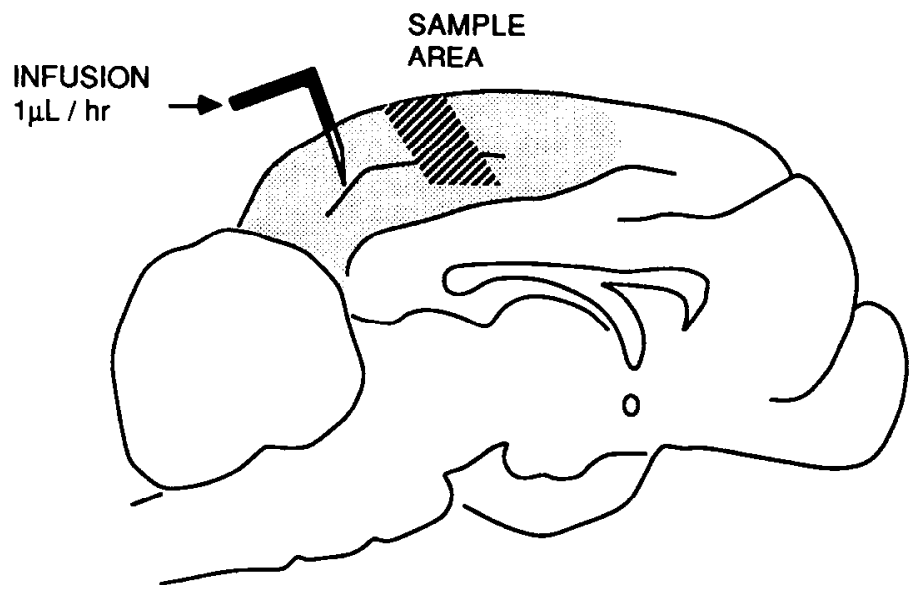

Figure 1. Top, Schematic illustration of a midsagittal view of a kitten brain to show area 17 (lightly stippled). Indicated is the approximate location of the infusion cannula through which APV was infused into the cortex. The region of striate cortex studied using single-unit recording (Sample Area) extended from approximately 3 to $6 \mathrm{~mm}$ from the site of infusion. Bottom, Chart to illustrate the various manipulations of visual experience and the type of drug treatment. Open bars represent time when the indicated eye $(L$, left eye; $R$, right eye) received normal patterned vision; filled bars represent time when the eye was deprived of vision. Thick horizontal lines indicate the duration and rate of APV infusion into area 17. The time (age) scale is indicated at the bottom of the chart $(P 7$, postnatal day 7 , the time of natural eye opening). $N$ refers to the number of APV-treated hemispheres studied in each experimental group. Refer to Table 1 for list of individual animals used for each experiment. Not shown on this graph are 2 control experiments (Table 1 , experiments $G$ and $H$ ).

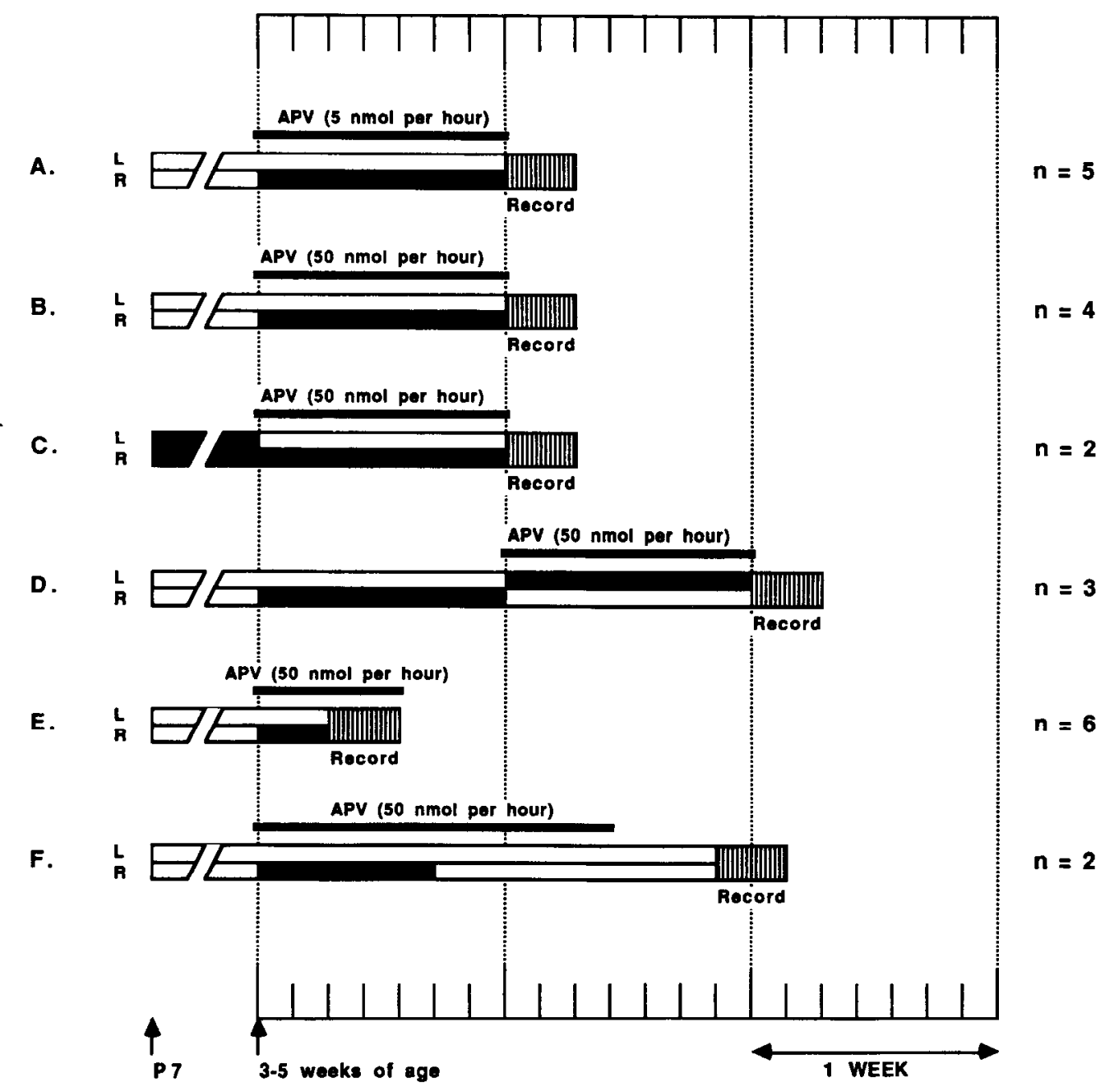

dominance sharply skewed toward the nondeprived eye. However, an unusually large fraction of recorded neurons lacked orientation tuning, and these same cells generally were also activated by stimulation of either eye. When the OD of all recorded neurons are pooled and APV-treated and control hemispheres compared, a small but significant difference is observed in the ocular dominance shift towards the nondeprived eye (Fig. 2, $A$, $B$ ). When neurons lacking orientation tuning (SEL categories 1 and 2) are considered separately (Fig. 3, $A, B$ ), it becomes clear that this population was unaffected by the monocular visual experience.

Another difference that was noted between APV-treated and control hemispheres in these experiments was a slight loss of RQ (Fig. 2, C, D). However, there was no clear relationship between reduced visual responsiveness and retention of binocular connections (Fig. 3, $C, D$ ). In addition, it should be noted 


\begin{tabular}{|c|c|c|c|c|c|c|}
\hline $\begin{array}{l}\text { Experi- } \\
\text { ment }\end{array}$ & Animal & Hemisphere & Treatment & $N$ & OED & B \\
\hline A & KBS165 & Left & D,L-APV & 80 & 0.52 & 0.46 \\
\hline A & & Right & None & 16 & & \\
\hline A & KBS167 & Left & D,L-APV & 35 & 0.39 & 0.56 \\
\hline A & & Right & None & 30 & 0.75 & 0.29 \\
\hline A & KBS172 & Left & D,L-APV & 39 & 0.58 & 0.44 \\
\hline A & & Right & - & - & & \\
\hline A & KBS 177 & Left & D,L-APV & 30 & 0.38 & 0.67 \\
\hline A & & Right & Saline & 19 & & \\
\hline $\mathbf{A}$ & KBS 178 & Left & D,L-APV & 26 & 0.46 & 0.42 \\
\hline A & & Right & - & - & & \\
\hline B & KBS185 & Left & D,L-APV & 28 & 0.35 & 0.50 \\
\hline B & & Right & Saline & 30 & 0.80 & 0.28 \\
\hline B & KBS 186 & Left & D,L-APV & 29 & 0.30 & 0.74 \\
\hline B & & Right & Saline & 28 & 0.71 & 0.31 \\
\hline B & KBS188 & Left & D,L-APV & 28 & 0.24 & 0.61 \\
\hline B & & Right & - & - & & \\
\hline B & KBS 190 & Left & D,L-APV & 28 & 0.37 & 0.78 \\
\hline B & & Right & Saline & 18 & & \\
\hline $\mathrm{C}$ & KBS 187 & Left & D,L-APV & 30 & 0.25 & 0.70 \\
\hline $\mathrm{C}$ & & Right & Saline & 25 & 0.83 & 0.21 \\
\hline $\mathrm{C}$ & KBS191 & Left & D,L-APV & 28 & 0.18 & 0.82 \\
\hline $\mathrm{C}$ & & Right & Saline & 30 & 0.71 & 0.31 \\
\hline $\mathrm{D}$ & GBS2.0 & Left & D,L-APV & 26 & 0.09 & 0.29 \\
\hline $\mathrm{D}$ & & Right & Saline & 28 & 0.69 & 0.30 \\
\hline D & GBS2.4 & Left & D,L-APV & 32 & 0.20 & 0.32 \\
\hline $\mathrm{D}$ & & Right & Saline & 30 & 0.73 & 0.21 \\
\hline D & GBS2.8 & Left & D,L-APV & 31 & 0.36 & 0.32 \\
\hline D & & Right & Saline & 22 & 0.97 & 0.06 \\
\hline $\mathrm{E}$ & GBS1.8 & Left $^{a}$ & D,L-APV & 20 & & \\
\hline$E$ & & Right & - & - & & \\
\hline$E$ & GBS2.5 & $\operatorname{Left}^{b}$ & D,L-APV & 33 & & \\
\hline $\mathrm{E}$ & & Right & - & - & & \\
\hline E & GBS2.7 & Left & D,L-APV & 20 & 0.22 & 0.85 \\
\hline E & & Right & D,L-APV & 18 & & \\
\hline $\mathrm{E}$ & GBS2.9 & Left & D,L-APV & 55 & 0.12 & 0.33 \\
\hline$E$ & & Right $^{c}$ & Saline & 49 & 0.69 & 0.43 \\
\hline E & GBS2.10 & Left ${ }^{c}$ & D,L-APV & 53 & 0.12 & 0.75 \\
\hline $\mathrm{E}$ & & Right $^{c}$ & Saline & 35 & 0.83 & 0.34 \\
\hline $\mathrm{F}$ & GBS1.4 & Left & D,L-APV & 29 & 0.31 & 0.59 \\
\hline $\mathrm{F}$ & & Right & None & 31 & 0.48 & 0.45 \\
\hline $\mathrm{F}$ & GBS1.5 & Left & D,L-APV & 30 & 0.22 & 0.56 \\
\hline $\mathrm{F}$ & & Right & Saline & 30 & 0.22 & 0.86 \\
\hline G & KBS 197 & Left & L-APV & 30 & 0.63 & 0.27 \\
\hline $\mathbf{G}$ & & Right & - & - & & \\
\hline $\mathrm{G}$ & KBS 198 & Left & - & - & & \\
\hline$G$ & & Right & L-APV & 30 & 0.91 & 0.18 \\
\hline $\mathbf{H}$ & $\mathrm{KBSCl}$ & Left & D,L-APV & 30 & 0.12 & 0.79 \\
\hline $\mathrm{H}$ & & Right & - & - & & \\
\hline $\mathrm{H}$ & GBSC1 & Left & D,L-APV & 31 & 0.10 & 0.87 \\
\hline $\mathbf{H}$ & & Right & Saline & 25 & 0.23 & 0.87 \\
\hline
\end{tabular}

Experiments A-F are schematically illustrated in Figure 1. Experiment G was identical to B except L-APV was infused into area 17 instead of D,L-APV. Experiment $\mathrm{H}$ was identical to B except that the subjects were adults. "Treatment" refers to the compound, if any, infused into area 17 at a rate of $1 \mu \mathrm{l} / \mathrm{hr}$. Manipulations of visual experience, durations of intracortical infusion, and concentrations of APV are indicated in Figure $1 . N$ refers to the number of neurons studied in each hemisphere. OED and B refer to the open-eye-dominance and binocularity indices, respectively, and are defined in the Materials and Methods. Values for OED and B are listed wherever it is appropriate.

a pilot study using a single tangential electrode penetration. Data not included in Figures 10 and 11.

${ }^{b}$ This kitten was not monocularly deprived.

"Iontophoresis was not used in these hemispheres. Data not included in Figure 10. 
APV (5 $\mathrm{nmol}$ per hour)

Figure 2. $A$ and $C$, Ocular dominance (OD) histograms compiled from units recorded in the striate cortex of 5 kittens that received an intracortical infusion of APV at a rate of $5 \mathrm{nmol} / \mathrm{hr}$ coincident with $7 \mathrm{~d}$ of monocular deprivation (see Fig. $1 A$ ). Neurons in OD category 5 were driven only by stimulation of the nondeprived eye; neurons in OD categories 2-4 were driven by stimulation of either eye (see Materials and Methods for classification scheme). The category labeled U contains those cells that could not be classified using visual stimuli. Also indicated in $A$ is the relative numbers of neurons in each OD category that were selective (SEL 3), biased (SEL 2), or aspecific (SEL 1) for stimulus orientation (see Materials and Methods for criteria). In $C$, the same OD data are illustrated showing the relative numbers of neurons in each category whose $R Q$ was rated as good (RQ3), fair (RQ 2), or poor (RQ 1; see Materials and Methods for criteria). $B$ units recorded in the control hemiwith APV. Conventions for $B$ are the same as for $A$; conventions for $D$ are the same as for $C$.

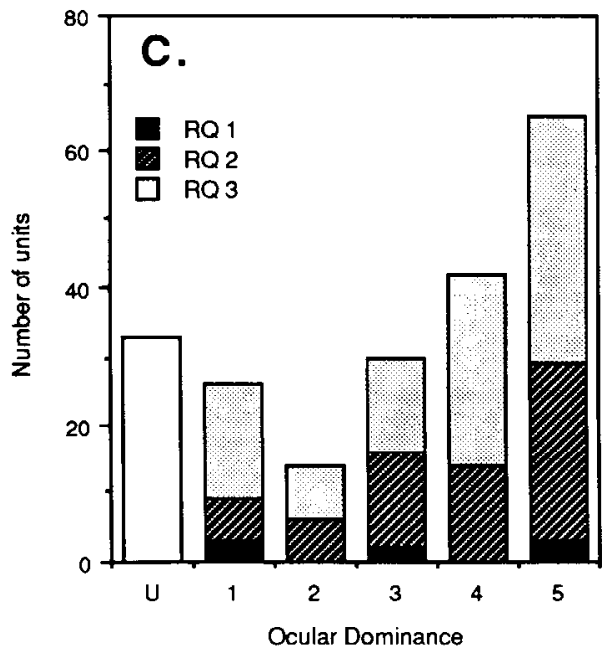

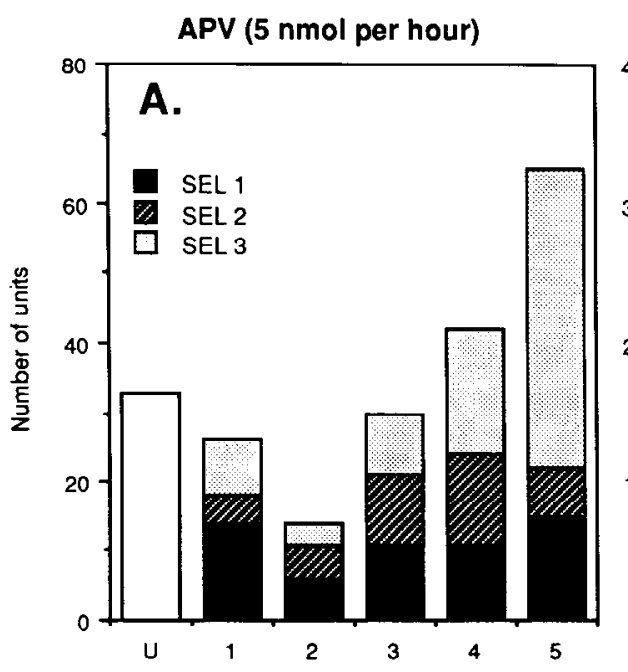
and $D$, OD histograms compiled from sphcres, contralateral to those treated
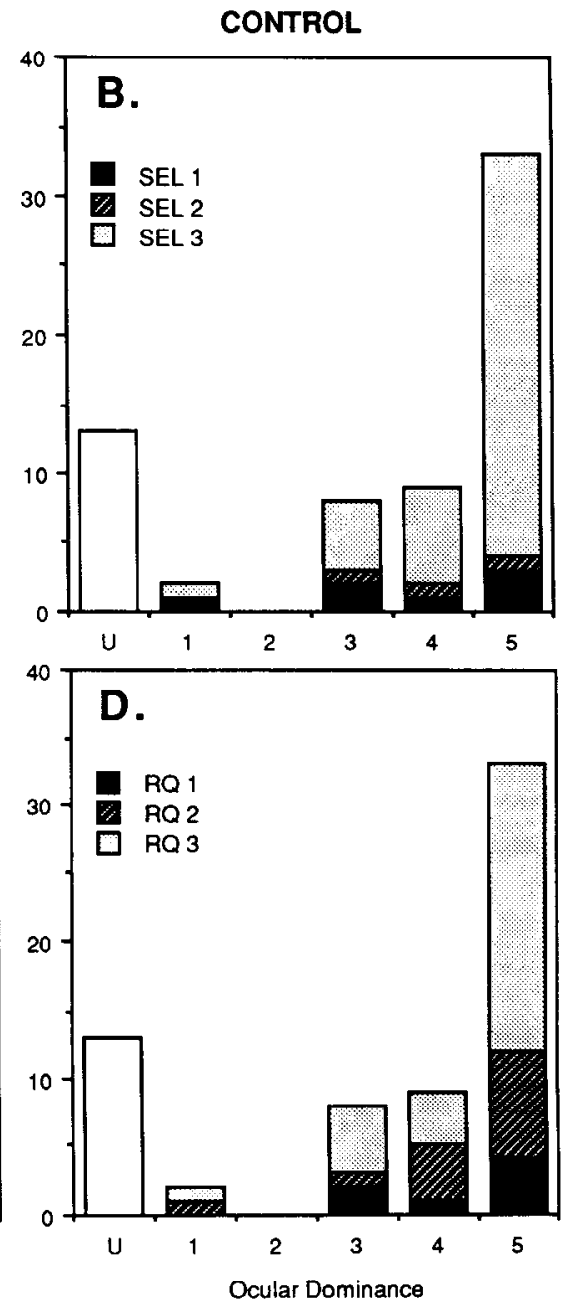

that there was no significant difference in the percentage of visually unclassifiable cells between experimental and control groups (Fig. 2).

In one animal whose visual cortex was infused with $5 \mathrm{~mm}$ APV (KBS165), a total of 80 single units was studied over a 48 $\mathrm{hr}$ period. The OD, SEL, and RQ in this case showed all the trends that were evident in the experimental group considered as a whole: an unusually large fraction of binocularly activated units that were untuned for stimulus orientation and a slight reduction in the overall RQ (Fig. 4). In this case, as in the others, the minipumps and infusion cannulae had been removed approximately $2 \mathrm{hr}$ prior to the onset of recording from area 17 . However, because of the length of the recording session in this experiment, it was possible to compare data obtained within 12 hr of pump removal when APV might still be present in the tissue, with those collected more than $1.5 \mathrm{~d}$ after pump removal when the NMDA receptor blockade has presumably been lifted completely. This comparison revealed no systematic differences in the occurrence of binocularly activated neurons lacking orientation selectivity, confirming that the consequences of APV treatment on the physiological organization of striate cortex outlast the presence of the drug.

One of the peculiar findings in the experiments utilizing a minipump concentration of $5 \mathrm{~mm}$ was that units with abnormal binocular receptive fields were found on the same electrode tracks as neurons with normal monocular fields. This occurred even very close to the site of infusion (1-2 mm anterior). When the data collected along single electrode tracks were analyzed with respect to electrode depth, it seemed as if the abnormal units (those that are relatively unselective and binocular) occurred mainly in superficial layers. Unfortunately, because we recorded with potassium citrate-filled pipettes, we were unable to recover the electrode tracks histologically. Nonetheless, the data are suggestive that at this concentration of APV, certain cortical layers may be more susceptible than others. This question requircs further study.

Having observed the slight but significant reduction in the OD shift in hemispheres treated with APV at $5 \mathrm{nmol} / \mathrm{hr}$, we naturally wondered if OD plasticity would be completely arrested if the drug concentration was increased. Therefore, the experiment was repeated with a 10 -fold higher APV concentration (Fig. 1B). The same effects that were evident with the lower APV concentration were observed in these cases, only now they occurred in the large majority of recorded neurons. Most units had poorly oriented, binocular receptive fields (Fig. $5, A, B$ ). In addition, there was a substantial decrease in the RQ of most cells, and there were more units that were visually unclassifiable (Fig. 5, C, D). Again, however, an ocular dominance shift still appeared to have occurred among the small fraction of orientation tuned $(\mathrm{SEL}=3)$ units (Fig. 5, $A, B)$. There was no such 
A. SELECTIVITY $=3$

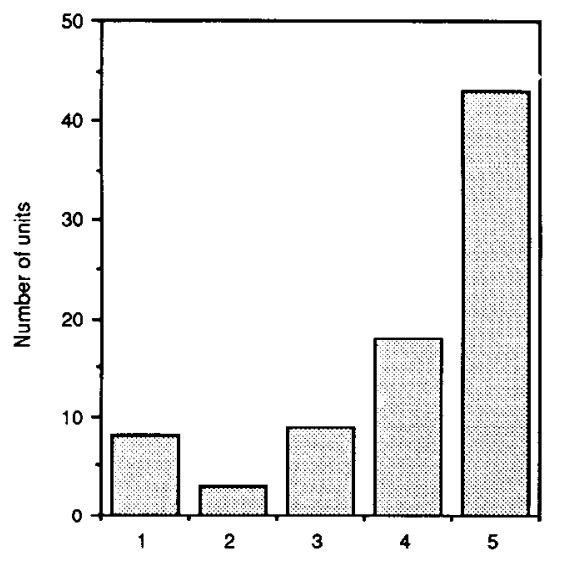

C. RESPONSE QUALITY $=3$

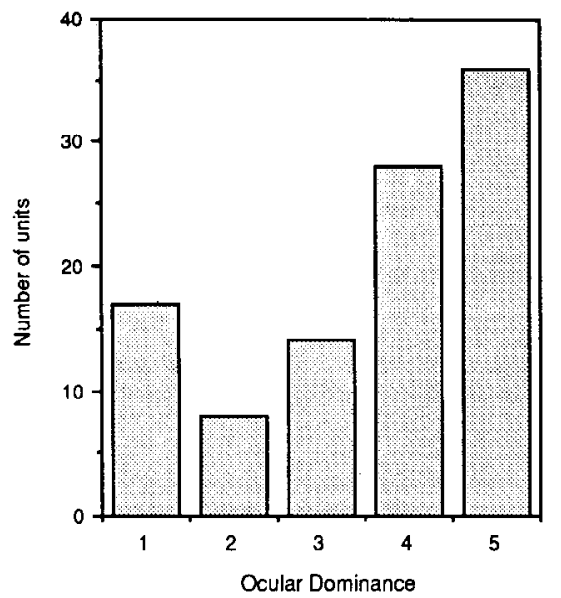

\section{B. SELECTIVITY $<3$}

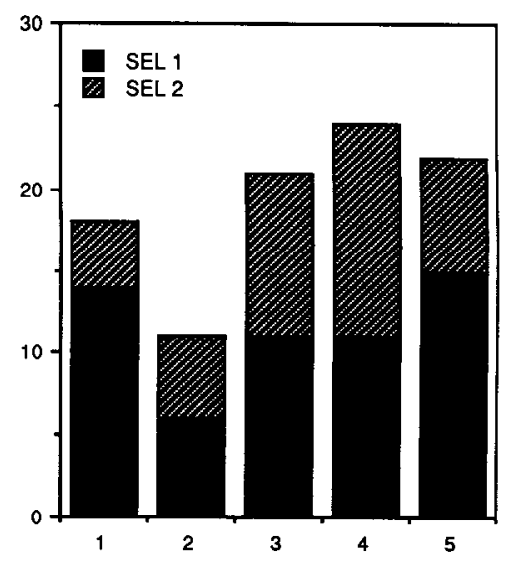

D. RESPONSE QUALITY $<3$

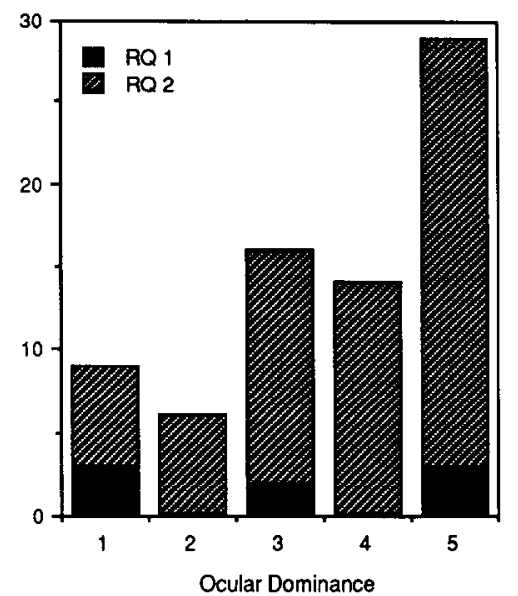

Figure 3. OD histograms compiled from units recorded in the striate cortex of 5 kittens that received an intracortical infusion of APV at a rate of $5 \mathrm{nmol} /$ hr coincident with $7 \mathrm{~d}$ of monocular deprivation (Fig. 1 $A$ ). $A$, OD histogram of neurons that were selective for stimulus orientation. $B$, OD histogram of neurons that responded to all stimulus orientations. $C$, OD histogram of neurons whose $R Q$ was rated as good $(R Q$ 3). $D$, OD histogram of neurons whose $\mathrm{RQ}$ was rated as fair to poor (RQ $1+$ 2). trend apparent in the population of recorded neurons whose response quality was rated as good $(\mathrm{RQ}=3$; Fig. $5, C, D)$.

The major findings of these experiments are summarized in Figures 6 and 7. Cortical APV treatment in monocularly deprived animals causes a concentration-dependent decrease in the OED index and a corresponding increase in the binocularity index (Fig. 6, $A, B$ ). Likewise, there is a marked dose-dependent change in the SEL index (Fig. 6C). The decrease in the RQ index with increasing APV concentration is comparatively mild and does not achieve statistical significance until $50 \mathrm{~mm}$ (Fig. 6D). As shown in Figure 7, there is a striking linear relationship between the loss of SEL and the decrease in OED with increasing APV concentrations. There is not a comparable rclationship between the $R Q$ index and OED, suggesting that the preservation of binocularity is not a direct consequence of decreased $R Q$ in these experiments. On the other hand, the loss of SEL and the preservation of binocular connections do appear to be closely associated.

\section{Other manipulations of visual experience during $50 \mathrm{mM} A P V$ infusion}

The changes observed in the physiological organization of striate cortex after MD reflect mainly the functional disconnection of synapses subserving the deprived eye. Our results indicate that this process is disrupted by APV. The previous experiments do not, however, address the question of whether the processes of synaptic strengthening or consolidation are also sensitive to NMDA receptor blockade in the visual cortex. In order to address this question, we designed experiments to reveal increases in the synaptic effectiveness of inputs from one eye in normal and APV-treated striate cortex.

In the first experiment, kittens were reared in complete darkness prior to monocular visual exposure (ME). Area 17 neurons in dark-reared kittens are poorly responsive to light stimuli, and the large majority are untuned for stimulus orientation. However, upon subsequent normal patterned visual experience, visual responsiveness and SEL rapidly mature (Frégnac and Imbert, 1984). To tcst whether this process is dependent on NMDA receptors, dark-reared kittens were given 1 week of monocular visual experience as striate cortex in one hemisphere was infused with APV at $50 \mathrm{nmol} / \mathrm{hr}$ (Fig. 1C).

The pooled results from 2 kittens (Table 1, experiment $C$ ) are illustrated in Figure 8. The recordings in the control hemispheres confirmed that visual responsiveness to stimulation of the experienced eye does increase markedly, as does SEL, after $7 \mathrm{~d}$ of contour vision. However, the units in the APV-treated hemispheres resembled those typical of striate cortex in visually naive, dark-reared animals. There were many unclassifiable cells, and those that could be classified were usually binocular and demonstrated poor RQ and SEL (Fig. 8A). Hence, it appears 

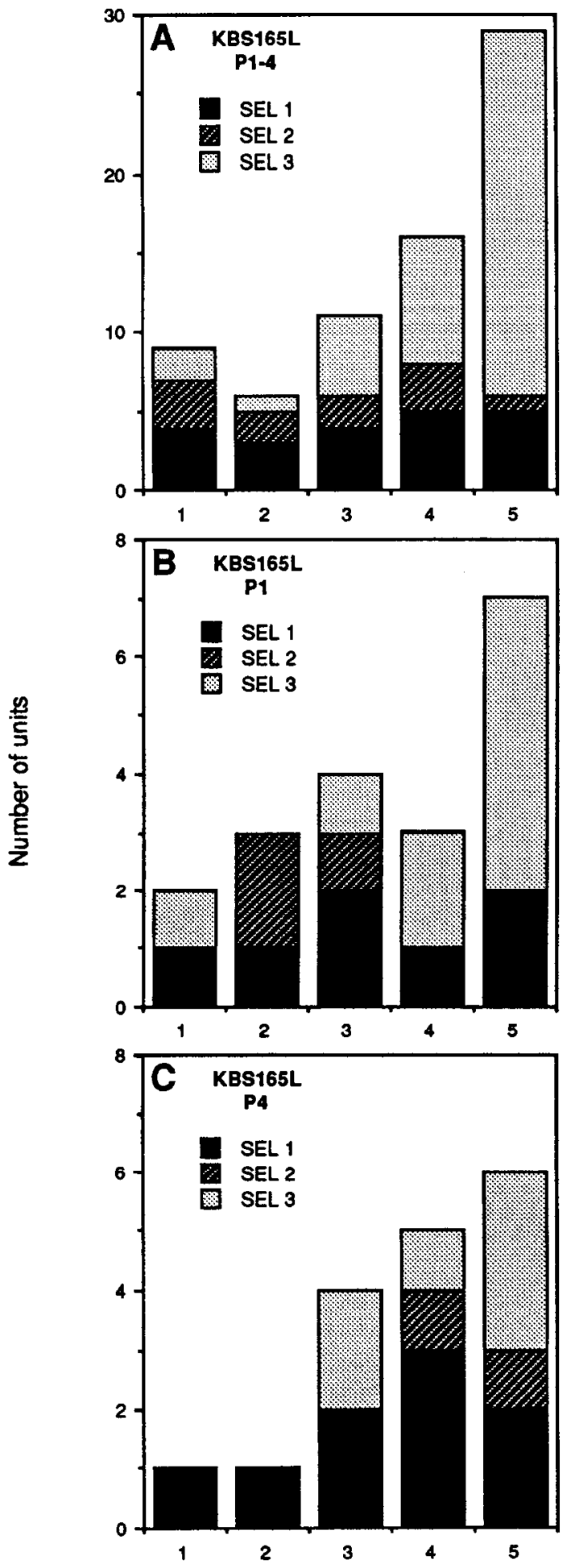

Figure 4. A, OD histogram of the 71 classifiable cells recorded in the striate cortex of animal KBS165L that had been infused with APV at $5 \mathrm{nmol} / \mathrm{hr}$ for 1 week coincident with monocular deprivation. $B$, OD histogram compiled from data collected on the first electrode track of case KBS165L, within $12 \mathrm{hr}$ of removing the APV-containing minipump. $C$, OD histogram compiled from the fourth electrode penetration, more than $32 \mathrm{hr}$ after removal of the minipump. In all cases, there is an unusually large fraction of neurons with binocular, unoriented receptive fields. that the acquisition of neuronal selectivity and responsiveness is completely blocked by APV treatment.

Another way to demonstrate increases in synaptic effectiveness in the visual cortex is to open the deprived eye after $7 \mathrm{~d}$ of MD and to suture the lids of the formerly nondeprived eye. After 1 week of "reverse suture" (RS), the formerly deprived eye completely recovers the ability to drive units in the visual cortex, while the newly deprived eye functionally disconnects (Blakemore and Van Sluyters, 1974; Rauschecker and Singer, 1979). To assess whether this process of functional recovery is sensitive to NMDA receptor blockade, in 3 kittens the striate cortex of one hemisphere was infused with APV at $50 \mathrm{nmol} / \mathrm{hr}$ during a period of RS (Fig. $1 D$ ).

The results of these RS experiments (Table 1, experiment D) are summarized in Figure 9 . In the control hemispheres, most neurons were tuned for stimulus orientation, and responsive only to stimulation of the recently open eye. In contrast, the newly opened eye failed to dominate the responses of most neurons in the APV-infused hemispheres; the majority of neurons were still responsive to the formerly open eye. There was also a large increase in the fraction of neurons that were untuned for stimulus orientation (Fig. 9A). The neurons in cortex treated with APV during RS differed from those recorded in the previous $\mathrm{MD}$ experiments (Fig. 5) in that their response quality was usually lower $(\mathrm{RQ}$ index $=0.31 \pm 0.10$ for $\mathrm{RS}$ vs $0.47 \pm$ 0.06 for $\mathrm{MD}$ ) and there were many more unclassifiable neurons ( $30 \%$ in RS experiments vs $15 \%$ in MD experiments). Decreased responsiveness would be expected if the RS led to a weakening of some inputs from the newly closed eye without a concomitant increase in the strength of inputs from the newly opened eye. Taken together, the results of these experiments are consistent with the idea that APV infusion interferes with the process of experience-dependent synaptic strengthening in striate cortex.

\section{Recordings during $50 \mathrm{~mm}$ APV infusion}

Increasing evidence indicates that NMDA receptors contribute importantly to the excitatory synaptic responses of cortical neurons to visual stimulation (Tsumoto et al., 1987; Fox et al., 1989; Miller et al., 1989). In a pilot study we investigated the effects of APV iontophoresis on the neuronal responses evoked by NMDA, glutamate and visual stimulation (Kleinschmidt et al., 1987). In agreement with Tsumoto et al. (1987), we found that APV frequently reduced, but never eliminated, the neuronal responses to retinal stimulation. In addition, APV iontophoresis did not alter direction or orientation selectivity. However, these experiments could not assess the degree to which APV infusion blocks light-evoked responses in our sample zone in area 17. To address this question, kittens were implanted with minipumps containing $50 \mathrm{~mm}$ APV and, 2 d later, recordings were made in area 17 with the pumps and infusion cannulae left in place (Fig. $1 E$ ). In most cases, the animals had also been monocularly deprived at the time of minipump implantation (Table 1, experiment E). Recordings usually were made with a Pt-Ir electrode with a 7-barreled microionophoresis pipette attached (Table 1). Phoresis barrels were filled with glutamate and NMDA so that we could activate otherwise silent neurons (see Materials and Methods).

The results of this experiment are illustrated in Figure 10. At distances $\leq 2.5 \mathrm{~mm}$ from the cannula, we recorded from 38 sites along 4 electrode tracks in 2 hemispheres (GBS2.5L and GBS2.9L, Table 1). In this zone, approximately half of the neurons which could be activated by application of glutamate were 
APV (50 nmol per hour)
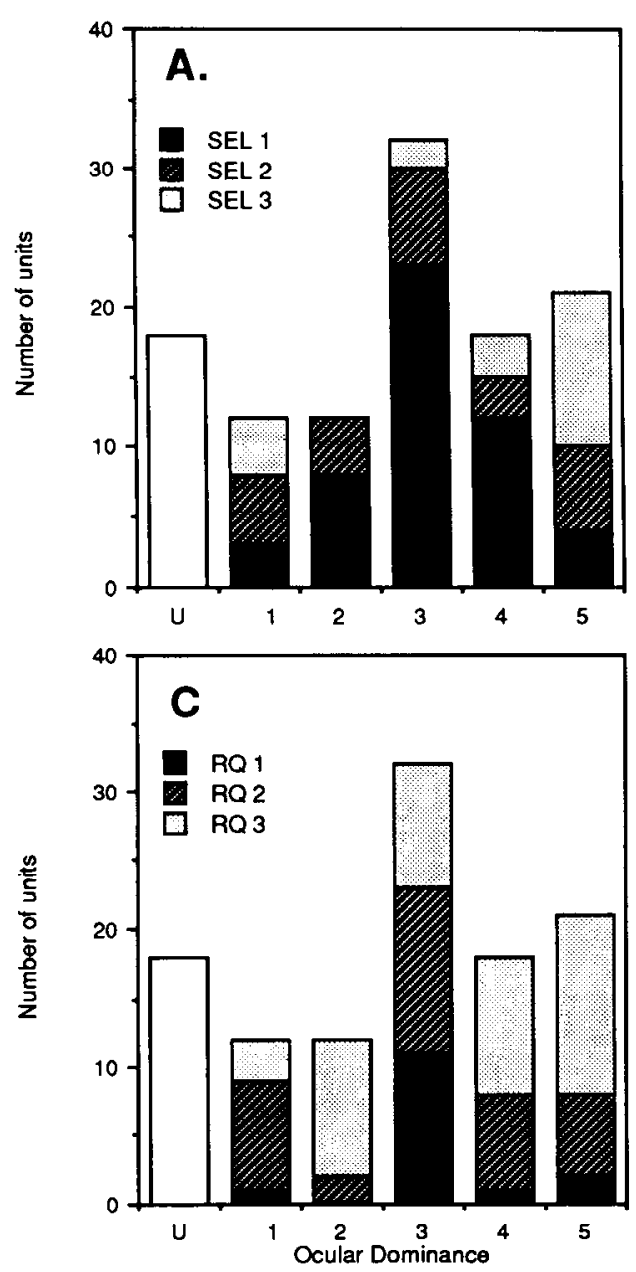

CONTROL
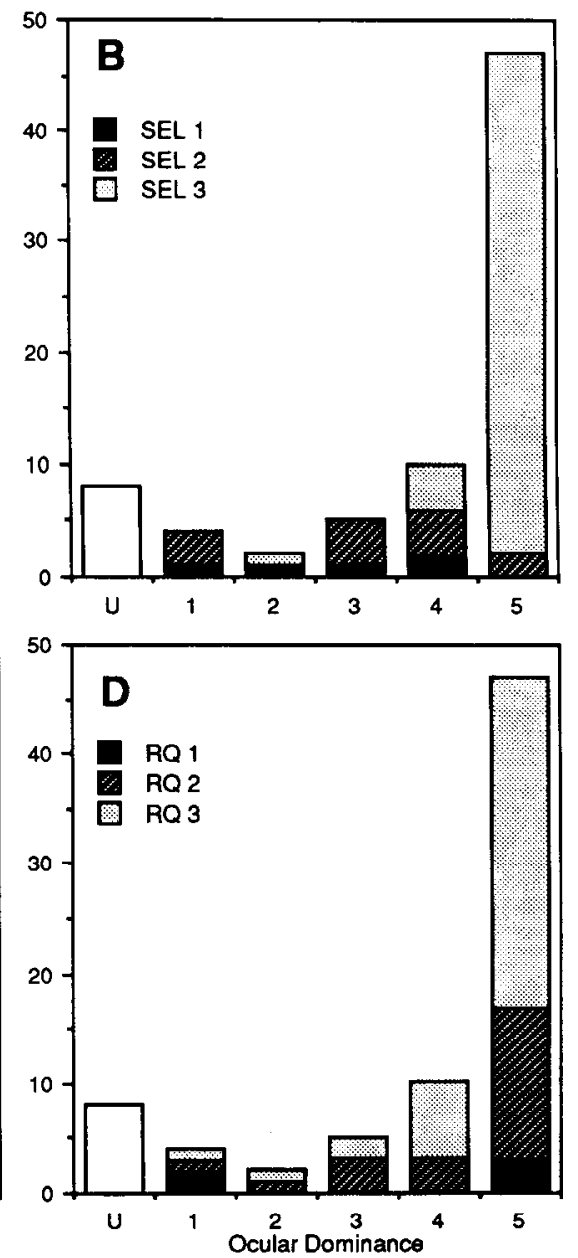

Figure 5. OD histograms compiled from units recorded in the striate cortex of 4 kittens that received an intracortical infusion of $50 \mathrm{mM} \operatorname{APV}(A, C)$ or saline $(B, D)$, coincident with $7 \mathrm{~d}$ of monocular deprivation (see Fig. $1 B$ ). All conventions are as for Figure 2. unresponsive to light stimuli. In addition, the visually responsive units had a generally poor response quality.

Between 3 and $6 \mathrm{~mm}$ from the APV infusion cannula, we collected data from 88 sites along 7 electrode tracks in 4 hemispheres (GBS2.5L, 2.7L, 2.7R, 2.9L, Table 1). The multiunit activity at $86 \%$ of these sites was driven by visual stimuli. This value does not differ significantly from the percentage of visually classifiable neurons recorded in the control hemispheres in this study ( $89 \pm 8 \%$; mean $\pm \mathrm{SD}, n=15$ ). From these results, we conclude that although visual responsiveness is clearly suppressed, particularly within $3 \mathrm{~mm}$ of the infusion cannula, the large majority of neurons in our sample zone (between 3 and 6 $\mathrm{mm}$; see Fig. 1) are responsive to light during APV infusion at $50 \mathrm{nmol} / \mathrm{hr}$.

Because one eyelid had been sutured closed in most cases (Table 1, experiment E), we also had the opportunity to study changes in ocular dominance in both saline-infused and APVtreated hemispheres after only $48 \mathrm{hr}$ of MD (Fig. 11). A strong ocular dominance shift toward the open eye was already evident in the 2 control hemispheres studied (Fig. 11C). However, we were surprised to find that a majority of units in the 4 APV. treated hemispheres were dominated by inputs from the deprived eye. When these units were analyzed as a function of distance from the cannula, it became clear that this "reverse shift" toward the deprived eye had occurred mainly in the region close to the site of infusion (Fig. 11A). Thus, it appears that high local concentrations of APV near the infusion cannula may promote a functional disconnection of the more active input, at least after $2 \mathrm{~d}$ of $\mathrm{MD}$.

\section{Other controls for specificity of APV effects}

The fact that a normal percentage of neurons was responsive to light in the sample zone during infusion of $50 \mathrm{~mm}$ APV suggests that the drug concentrations were in a range where they were selective for NMDA receptors (Tsumoto et al., 1987). However, we performed several additional experiments and analyses to address the following questions concerning the specificity of the observed APV effects:

1. Are the effects of D,L-APV infusion stereospecific?

2. Does chronic APV infusion disrupt receptive field organization in adult area 17 ?

3. Are the effects of APV infusion caused by permanent structural damage to cortex?

4. Is the extracellular concentration of APV in the sample zone in a range considered to be effective for blocking synaptic modifications in vitro?

Are the effects of $D, L-A P V$ infusion stereospecific? This question was addressed by repeating the MD experiment illustrated in 


\section{A. OPEn EYe dominance}

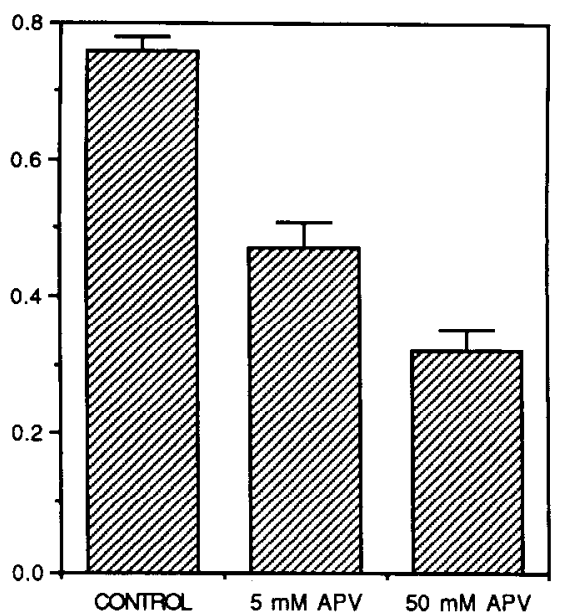

C. ORIENTATION SELEctivity

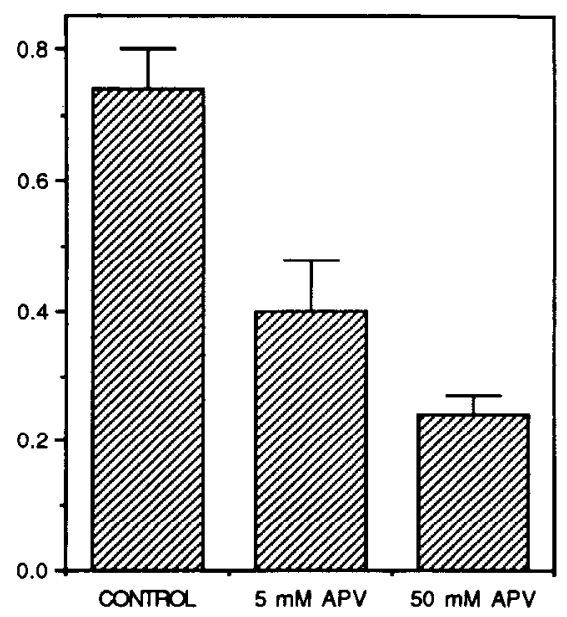

B. BINOCULARITY

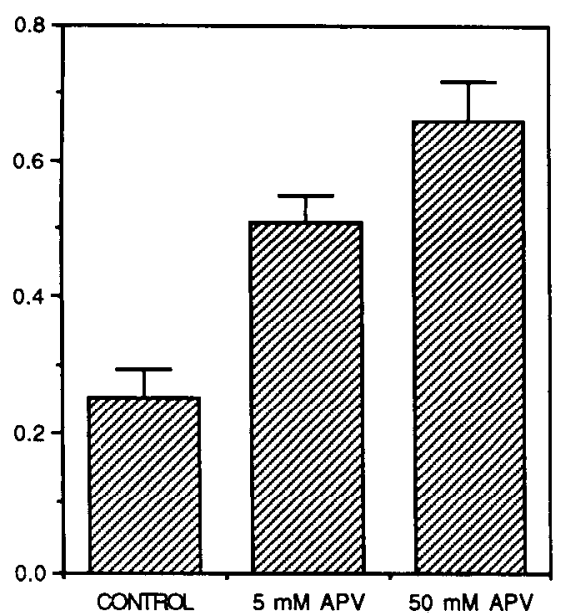

D. RESPONSE QUALITY

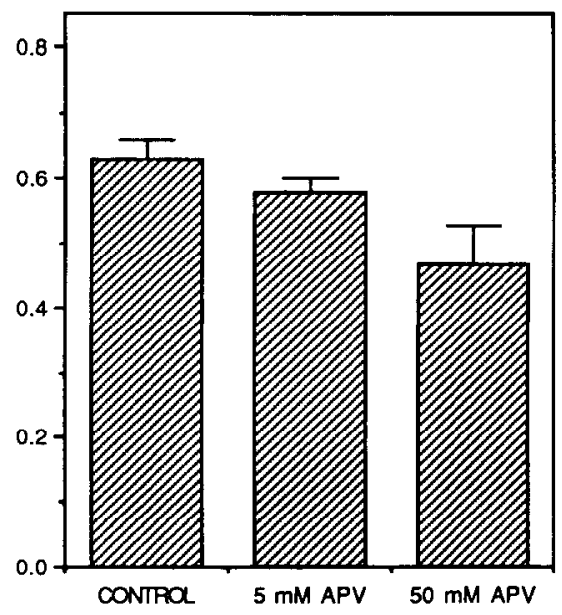

Figure 6. The mean \pm SEM of the OED index $(A)$, the Binocularity index $(B)$, the SEL index $(C)$, and the RQ index $(D)$ calculated from recordings in the hemispheres of the saline-infused group $(n=3)$, the group infused with 5 mM APV $(n=5)$, and the group infused with $50 \mathrm{~mm}$ APV $(n=4)$. See Materials and Methods for the definitions of these indices. In all groups, the infusion was coincident with 1 week of monocular deprivation (Fig. $1 A, B$ ). One-way analysis of variance confirms that the APVtreated groups differ significantly from control for all indices with the exception of the RQ index of the $5 \mathrm{~mm} \mathrm{APV}$ group.
Figure $1 B$ using the pharmacologically inactive stereoisomer LAPV. The results from 2 kittens (Table 1, experiment G) revealed that intracortical infusion of $50 \mathrm{~mm}$ L-APV had no effect on the cortical response to a week of MD. Most neurons were clearly dominated by the nondeprived eye, and the large majority were orientation selective. These results indicate that the effects observed after infusion of D,L-APV are likely due to an action of the D-stereoisomer. This result would be expected if the observed effects of D,L-APV were due specifically to the blockade of NMDA receptors because the $D$ form has an approximately 100 -fold greater affinity for the receptor than does the $\mathrm{L}$ form (Watkins and Evans, 1981).

Does chronic APV infusion disrupt receptive field organization in adult area 17? The results obtained in kittens suggest that APV infusion disrupts both the maintenance and modification of neuronal response properties during the critical period. These properties can also be disrupted by environmental deprivation during this period, but not in adulthood. In order to address the question of whether the APV effects are also limited to the plastic period, 2 adult cats were monocularly deprived and their striate cortex infused with $50 \mathrm{~mm}$ APV for 1 week (Table 1, experiment $\mathrm{H}$ ). Recordings were made as usual, after removing the pumps and infusion cannulae. These experiments revealed no systematic differences between the APV-and saline-infused hemispheres. Most neurons were vigorously responsive to light, binocular, and sharply tuned for stimulus orientation. Thus, it appears that chronic APV infusion disrupts receptive field organization only during the critical period for experience-dependent synaptic modifications.

Are the effects of APV infusion caused by permanent structural damage to cortex? There is no denying that infusion of substances into the cortex at $1 \mu \mathrm{l} / \mathrm{hr}$ for 1 week through chronically implanted cannulae can lead to a sizable region of necrosis. However, this seems to occur regardless of the actual drug used. As Paradiso et al. (1983) have reported, we found that lesions as large as $3 \mathrm{~mm}$ in diameter occur in tissue infused only with saline. Inspection of the histology in APV-trcatcd hcmispheres revealed no systematic differences in the size of this lesion as compared with control. Furthermore, examination of the sample zone between 3 and $6 \mathrm{~mm}$ from the cannulae in Nissl-stained sections did not uncover any gross abnormalities in the cytoarchitecture of striate cortex treated with APV. Nonetheless, the 


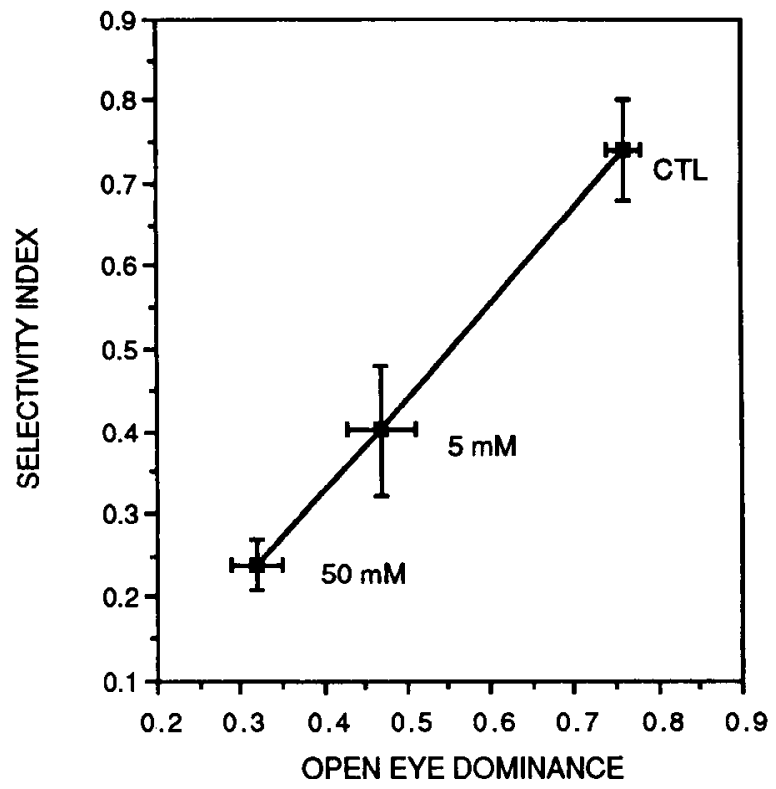

Figure 7. Means \pm SEM of the SEL index are plotted against the means \pm SEM of the OED index for the 3 experimental groups illustrated in Figure 9. A decrease in the SEL index reflects a decrease in the percentage of orientation-selective neurons; a decrease in the OED index reflects a decreased OD shift toward the open eye after a period of monocular deprivation (see Materials and Methods). These 2 indices were found to change in parallel as APV concentrations were increased.

claim has been made that $50 \mathrm{~mm}$ APV infusion can destroy neurons in striate cortex as far away as our sample zone (Rauschecker, personal communication). In order to assess whether such an effect might have contributed to our results, we performed an analysis of the frequency of sampling single units in tissue infused with saline, $5 \mathrm{~mm} \mathrm{APV}$, and $50 \mathrm{~mm}$ APV. The distances between successively recorded units were calculated for each penetration in each experiment, and these values assigned to $50 \mu \mathrm{m}$ bins. The results of this analysis are shown in Figure 12. The differences between experimental groups are not statistically significant. This suggests that neuronal density in the region of cortex which we sampled is not decreased signif- icantly as a consequence of APV infusion. This agrees with cell counts which showed no difference between APV- and salineinfused hemispheres up to $4 \mathrm{~mm}$ from the border of the necrosis (Gu et al., 1989).

Still, the data clearly indicate that infusion of $50 \mathrm{~mm} \mathrm{APV}$ into striate cortex during the critical period increases the percentage of unclassifiable neurons and decreases the RQ of many cells with visual receptive fields. Analysis of RQ in 2 kittens (Table 1, experiment F) that were allowed $3 \mathrm{~d}$ to recover from APV infusion (Fig. $1 F$ ) showed that neuronal response quality can return to normal levels after cessation of drug treatment (Fig. 13). This makes it unlikely that the decreased visual responsiveness observed in APV-treated cortex results from neuronal degeneration or other permanent structural damage.

Is the extracellular concentration of APV in the sample zone in a range considered to be effective for blocking synaptic modifications in vitro? In order to assess the spatial distribution of APV during intracortical infusion, we infused ${ }^{3} \mathrm{H}-\mathrm{APV}$ at a rate of $50 \mathrm{nmol} / \mathrm{hr}$ for $4 \mathrm{~d}$ into 4 hemispheres. The brains were frozen in situ and the lateral gyri dissected. ${ }^{3} \mathrm{H}$-APV was measured in coronal slices of area 17 and expressed as nmol APV/mg tissue, wet weight (see Materials and Methods). In the region of striate cortex between 3 and $6 \mathrm{~mm}$ from the cannula, the tissue APV content ranged from $1.06 \pm 0.26$ to $0.55 \pm 0.07$ (mean \pm SEM) $\mathrm{nmol} \mathrm{APV} / \mathrm{mg}$ tissue.

The measured APV content of the tissue reflects free APV in the extracellular fluid, APV specifically bound to NMDA receptors, nonspecific binding of APV to membranes, and possibly the internalization of some APV. The measure of interest is the extracellular concentration because data from in vitro slice experiments indicate that APV concentrations in the range of $\sim 100 \mu \mathrm{M}$ block NMDA receptor mediated EPSP components without affecting the non-NMDA receptor mediated EPSP in adult rat visual cortex (Artola and Singer, 1987). We therefore measured the accumulation of APV by living slices of visual cortcx soakcd in known concentrations of ${ }^{3} \mathrm{H}-\mathrm{APV}$. Figurc $14 \mathrm{~A}$ shows the accumulation of APV by slices incubated in $150 \mu \mathrm{M}$ APV for various times. The tissue content of APV becomes asymptotic at times $\geq 18 \mathrm{hr}$, when it measures $0.59 \pm 0.03$ $\mathrm{nmol} / \mathrm{mg}$ tissue. As shown in Figure 14B, nmol APV/mg tissue at $\geq 18 \mathrm{hr}$ is linear with respect to extracellular (bath) APV
A.

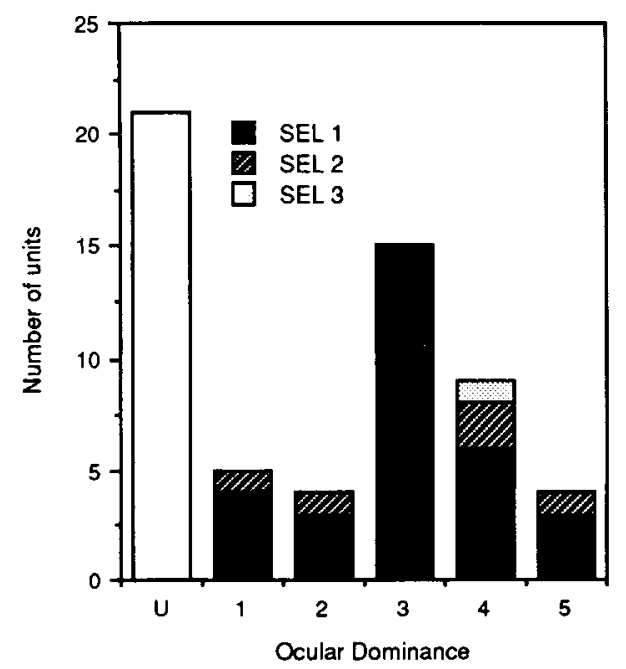

B.

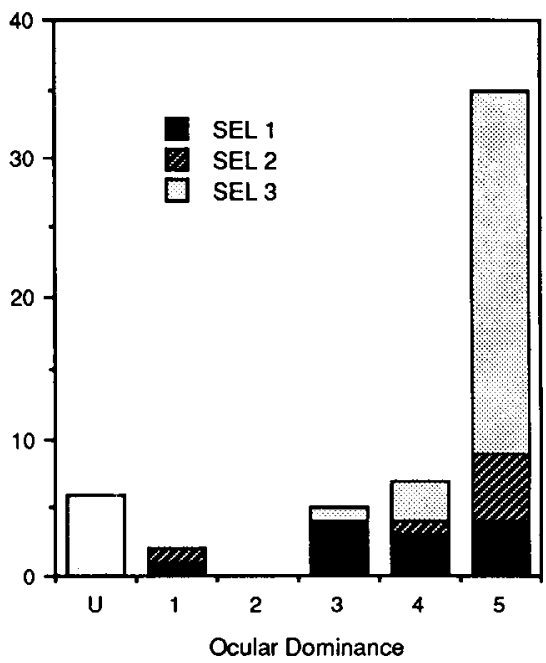

Figure 8. OD histograms compiled from units recorded in the striate cortex of 2 kittens that had been raised in complete darkness prior to receiving 1 week of monocular visual experience (see Fig. IC). $A$, Units in the hemispheres that received an intracortical infusion of 50 mM APV coincident with the MD. The SEL of the units in each OD histogram is also indicated. $B$, Units recorded in saline-infused control hemispheres. All conventions are as for Figure 2. 
A.

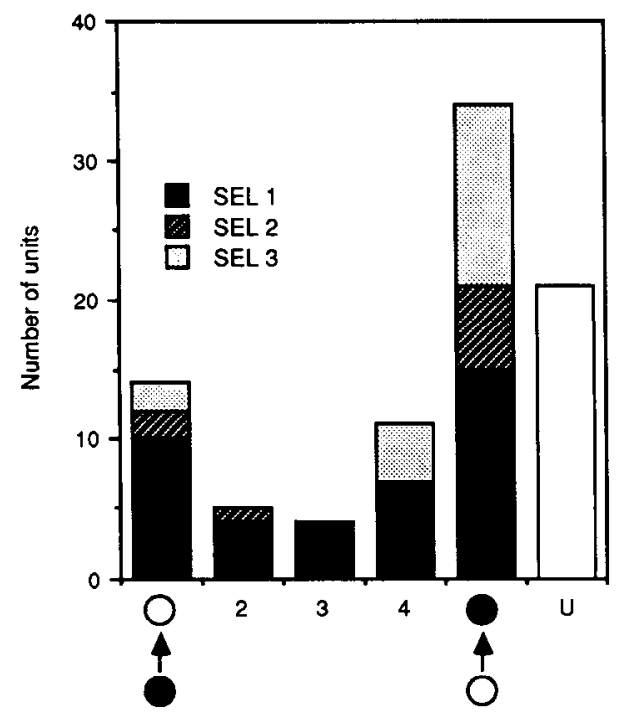

B.

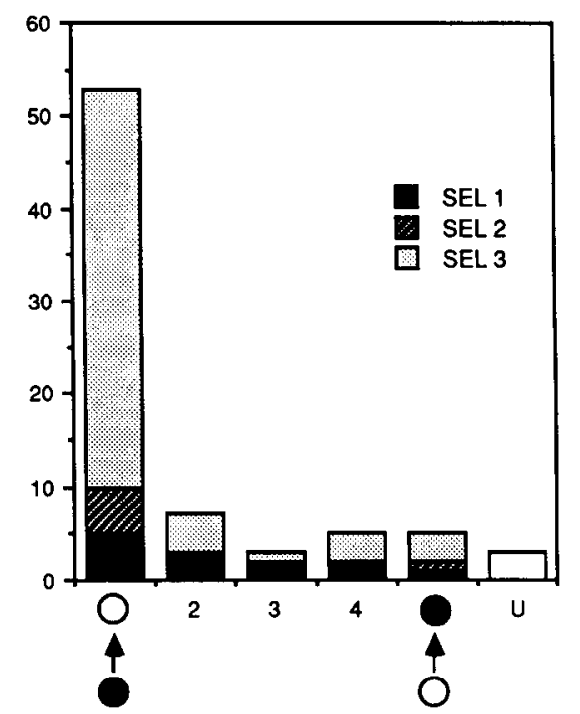

Figure 9. In this experiment, the right eyelids of 3 kittens were sutured closed at about 4 weeks of age. One week later, these lids were opened, and the left eyelids closed. At this time, minipumps were implanted that infused $50 \mathrm{mM}$ APV into one hemisphere and saline into the other. After 1 weck, the cortex was assayed for changes in ocular dominance and selectivity (see Fig. $1 D$ ). $A$, OD histogram of units in the APV-treated hemispheres. The OD category representing units responsive to the most recently deprived eye is indicated by the filled circle (category 5). B, OD histogram of units recorded in the control hemispheres. Conventions are as for $A$. concentration up to $500 \mu \mathrm{M}$. From these data, it was possible to convert our measures of tissue APV content as a function of distance from the cannula into specific extracellular concentrations. These results are shown in Figure $14 \mathrm{C}$. This calculation yields a concentration range of $150-250 \mu \mathrm{M}$ in the sample zone

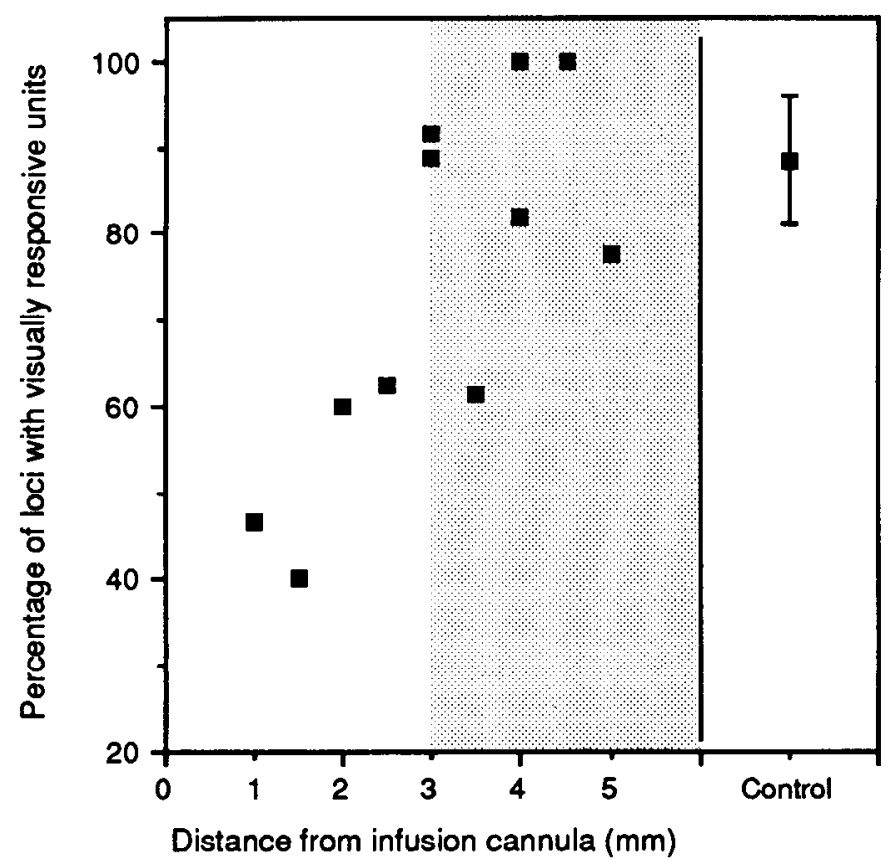

Figure 10. Plot indicating the percentage of loci with visually responsive units at different distances from the infusion cannula. Each point was calculated from data collected along a single electrode track. The data were collected from 4 hemispheres in 3 kittens (GBS2.5, 2.7, 2.9; see Table 1). The lightly stippled area shows the usual neurophysiological sample zone. Recordings were made as APV was infused at $50 \mathrm{nmol} /$ $\mathrm{hr}$, on the third day of infusion (see Fig. $1 E$ ). Glued to the recording electrode was a 7-barreled microionophoresis pipette which was used to apply glutamate or NMDA to activate otherwise silent units. The point labeled "control" is the mean $( \pm \mathrm{SD})$ percentage of visually responsive neurons in 15 control hemispheres. between 3 and $6 \mathrm{~mm}$ from the cannula when $50 \mathrm{~mm} \mathrm{APV} \mathrm{is}$ infused.

\section{Discussion}

The results of these experiments indicate that intracortical infusion of $D, L-A P V$ for 1 week during the critical period gradually disrupts the response properties of visual cortical neurons in a concentration-dependent fashion and makes them resistant to the effects of manipulating the visual environment.

\section{Mechanism of APV action on visual cortical plasticity}

There are several reasons to believe that the effects of APV infusion are due specifically to the blockade of cortical NMDA receptors. First, the effects depend on the presence of the pharmacologically active D-stereoisomer of APV because infusion of L-APV was without effect. Second, our calculations indicate that statistically significant effects of APV infusion can be observed with intracortical concentrations as low as $\sim 20 \mu \mathrm{M}$ (with a minipump concentration of $5 \mathrm{~mm}$ ). The ocular dominance shift after MD was almost completely blocked with APV concentrations of $\sim 200 \mu \mathrm{M}$ (with a minipump concentration of 50 $\mathrm{mM}$ ). These are concentrations used in slices of visual cortex and hippocampus to provide a selective blockade of NMDA receptors (Harris et al., 1984; Artola and Singer, 1987). Third, recordings during $50 \mathrm{~mm}$ APV infusion reveal a normal percentage of neurons with visual receptive fields at distances greater than $3 \mathrm{~mm}$ from the cannula (Fig. 10). This result would not be expected if both NMDA and non-NMDA EAA receptors were blocked at these sites (Tsumoto et al., 1987). An experiment by Miller et al. (1989) also supports the notion that intracortical infusion of APV provides a selective blockade of the NMDA subtype of EAA receptor. They studied visual responsiveness and sensitivity to ionophoretically applied NMDA and kainate in the adult visual cortex during infusion of $50 \mathrm{mM} \mathrm{D,L-}$ APV. They find that after $1 \mathrm{~d}$ of infusion, $\sim 85 \%$ of recorded sites show reliable visual responses at distances $\geq 4 \mathrm{~mm}$ from the infusion cannula. However, in addition, they report that the activation threshold for kainate is unaffected by the APV treatment, even within $2 \mathrm{~mm}$ of the cannula. Taken together, the 

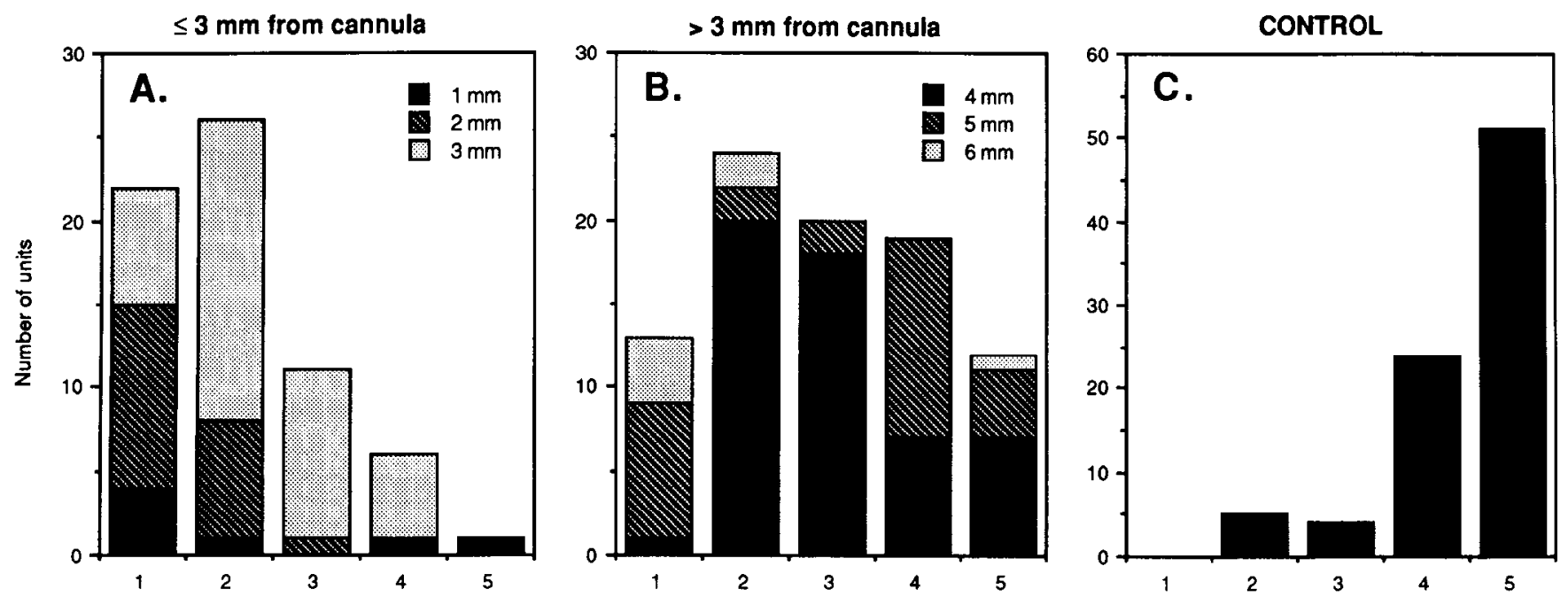

OCULAR DOMINANCE

Figure 11. OD histograms compiled from units recorded on the third day of an APV infusion into area 17 that was coincident with MD (see Fig. $1 E$ ). These data were collected from 6 hemispheres in 3 kittens (GBS2.7, 2.9, 2.10; Table 1). $A$, Units recorded $\leq 3 \mathrm{~mm}$ from the infusion cannula. $B$, Units recorded $>3$ and $\leq 6 \mathrm{~mm}$ from the infusion cannula. $C$, Units recorded in 2 control hemispheres. In all histograms, units that were activated exclusively by stimulation of the nondeprived eye are in OD category 5 . Of the 68 visually responsive units studied $\leq 3 \mathrm{~mm}$ from the APV infusion cannula in 3 hemispheres, only 1 was assigned to OD category 5; the majority of cells were dominated by input from the deprived eye.

data indicate that the effects we observe are due to the selective blockade of visual cortical NMDA receptors during the critical period.

How does the chronic blockade of NMDA receptors result in the apparent disruption of synaptic modification in area 17? The average response quality of visual cortical neurons is decreased both during and after infusion of $50 \mathrm{~mm} \mathrm{APV}$. Similar observations by Rauschecker (personal communication) have led him to suggest that chronic NMDA receptor blockade actually leads to neuronal cell death in the neurophysiological sample zone. As previously reported by Paradiso et al. (1983), we find that intracortical infusion leads to a substantial lesion in the cortex that will occur with saline alone. Inspection of the histology in our cases has revealed no systematic differences in the size of this lesion, or in the cytoarchitecture of the sample zone, between APV-treated and control hemispheres (see also $\mathrm{Gu}$ et al., 1989). Furthermore, although the data clearly show that the response quality is diminished in the cortex treated with $50 \mathrm{~mm}$ APV (Figs. 5, 6), there does not appear to be a significant reduction in the frequency of sampling neurons with our electrodes (Fig. 12), and the decrease in RQ evidently is not irreversible (Fig. 13). Finally, statistically significant effects on SEL and OD are observed after infusion of $5 \mathrm{~mm}$ APV, which does not significantly increase the percentage of visually unclassifiable or poorly responsive neurons (Figs. 2,6 ). Therefore, we conclude that dramatic changes in the physiological organization of striate cortex can be induced by APV treatment in the absence of overt neurotoxicity.

\section{NMDA receptor blockade vs cortical activity blockade}

We have shown that APV infusion disrupts OD plasticity in locations where a normal percentage of cortical neurons are visually responsive (Figs. 10,11). ${ }^{1}$ Hence, these results may be

' Recently, Miller et al. (1989) have shown that infusion of $50 \mathrm{~mm}$ APV into adult visual cortex can profoundly suppress visual responses at sites close to the distinguished from those of other studies that caused gross disturbances of cortical activity (Shaw and Cynader, 1984; Reiter et al., 1986; Stryker and Harris, 1986; Reiter and Stryker, 1988). Nonetheless, because NMDA receptors presumably are at least partially blocked at these sites, it would be surprising indeed if the absolute level of visual response was not reduced in many neurons (see, for example, Fox et al., 1989). This fact does not detract from the significance of the present findings; the data clearly demonstrate that visual responses generated in the absence of sufficient NMDA receptor activation are not sufficient to induce changes in cortical OD.

The possibility remains that the partial suppression of visually evoked activity caused by APV is alone responsible for the disruption of OD plasticity, irrespective of the NMDA receptor blockade. This hypothesis predicts that all manipulations which decrease cortical activity should yield similar results. Indeed, destruction of the facilitatory cholinergic and noradrenergic inputs leaves cortex resistant to the effects of MD (Bear and Singer, 1986). However, unlike the effects of APV, destruction of the modulatory inputs has no discernible effect on orientation selectivity and does not produce a comparable lasting decrease in visual responsiveness. Likewise, the inactivation of all cortical activity (both pre- and postsynaptically) with intracortical tetrodotoxin prevents the OD shift after MD without affecting other response properties (Reiter et al., 1986). Complete blockade of postsynaptic spike activity with an intracortical infusion of the $\mathrm{GABA}_{\mathrm{A}}$ agonist muscimol produces a shift of OD away from the experienced eye after MD (Reiter and Stryker, 1988) that resembles what we observed near the cannula after $2 \mathrm{~d}$ of APV infusion (Fig. 11). However, unlike what we have observed with APV, Reiter and Stryker did not note a loss of selectivity after chronic muscimol treatment. They also did not find that

infusion cannula. Their results are in close agreement with our own observations (illustrated in Fig. 10). These findings do not change the conclusion that APV still disrupts plasticity at sites $\geq 4 \mathrm{~mm}$ from the cannula where a normal percentage of neurons are visually responsive. 
SAMPLE FREQUENCY
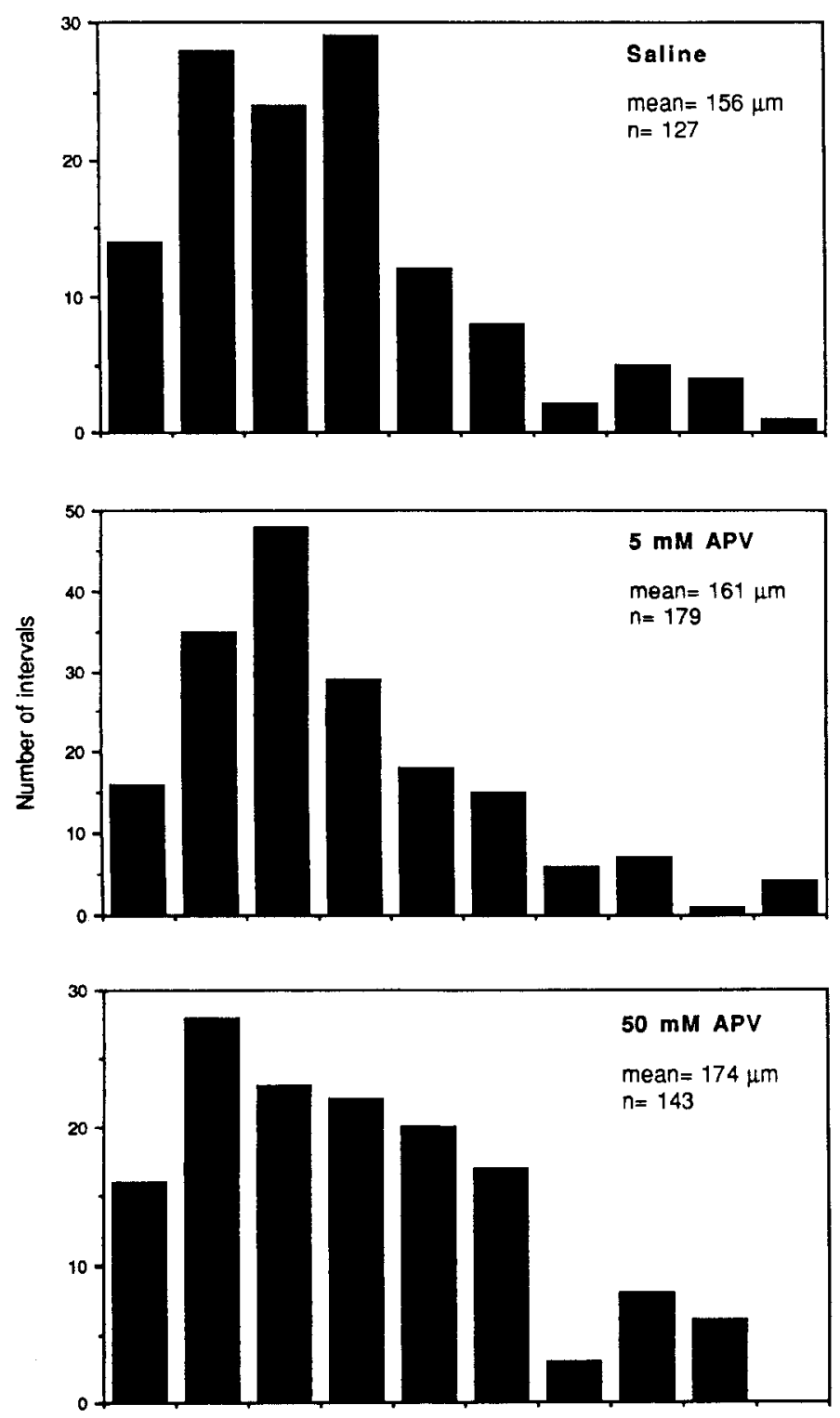

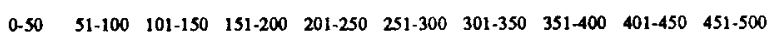

Distance between successively recorded units $(\mu)$

Figure 12. Analysis of the frequency of sampling single units in the striate cortex of saline-infused hemispheres (top), hemispheres infused with $5 \mathrm{mM}$ APV (middle), and hemispheres infused with $50 \mathrm{~mm}$ APV (bottom). The distance between each successively recorded unit on each electrode track was assigned to one of nine $50-\mu \mathrm{m}$-wide bins. The histograms show the number of interunit intervals within these bins; $n$ refers to the total number of intervals for each experimental group (intervals $>500 \mu \mathrm{m}$ were not included). The distributions of interunit intervals do not differ significantly between these three groups.

sites were predominantly binocular at distances from the cannula where responses were only partially suppressed. Thus, it is not clear that all these results can be explained by the suppression of postsynaptic activity alone

The consequences of chronic NMDA receptor blockade do resemble those characteristic of binocular deprivation, namely, a loss of selectivity and RQ (Freeman et al., 1981; Rauschecker
Case

Response Quality Index

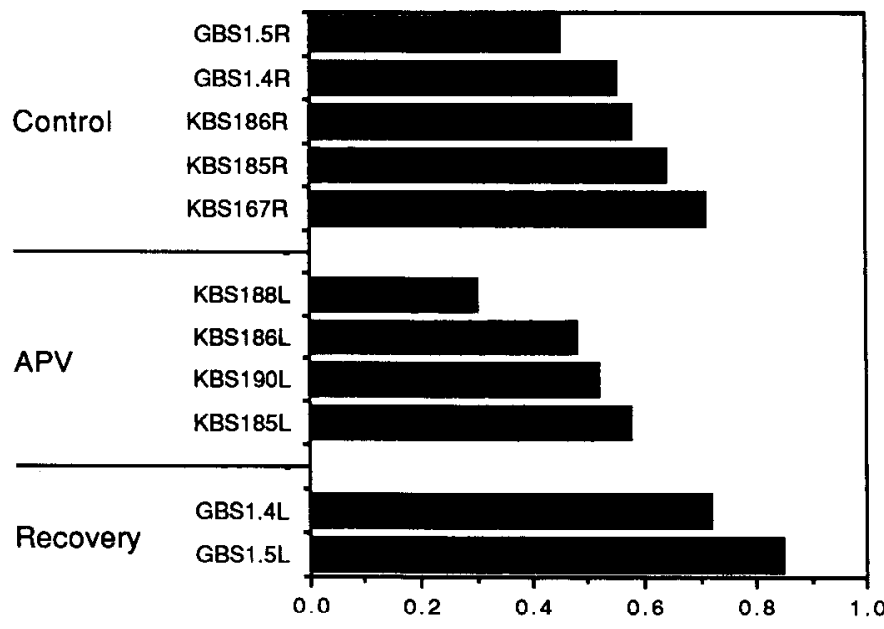

Figure 13. The RQ index is plotted for hemispheres in which $>20$ units were visually classifiable. The control group includes the salineinfused hemispheres in kittens that were monocularly deprived (KBS167, $185,186)$ or given binocular visual experience after MD (GBS1.4, 1.5). The APV group includes the monocularly deprived kittens that were studied within $48 \mathrm{hr}$ of the cessation of $50 \mathrm{~mm}$ APV infusion (Fig. $1 B$ ). The group marked "Recovery" includes the 2 animals that were studied $\geq 3 \mathrm{~d}$ after ending the APV infusion (see Fig. $1 F$ ).

and Singer, 1982; Frégnac and Imbert, 1984). During binocular deprivation the afferents from both eyes are active, but this activity is unstructured "noise" and therefore is incapable of driving cortical neurons. Normally during MD, the afferents from the open eye are at a competitive advantage presumably because they convey temporally and spatially coherent patterns of activity. Hence, the APV effects we describe could be explained if chronic NMDA receptor blockade caused cortical neurons to "view" coherent input patterns as noise. Indeed, the voltage-dependent NMDA receptor mechanism is ideally suited to detect correlated input activity.

The despecification of visual receptive field properties after chronic APV infusion in kitten area 17 may be analogous to the effects reported by Cline et al. (1987) of APV applied to the optic tecta of tadpoles with a grafted supernumerary eye. Under the influence of normal visual experience, the retinal inputs to the tectum segregate into OD stripes similar to those observed in layer IV of striate cortex. The chronic application of APV to the surface of the tectum causes the retinal terminals to desegregate, an effect that is reversed upon removal of the APV. The authors have suggested that NMDA receptor activation is necessary for synaptic stabilization in this system. Similarly, there is recent evidence that $\mathrm{NMD \Lambda}$ receptor activation is a critical variable in the stabilization of the isthmotectal projection in Xenopus (Scherer and Udin, 1988) and the regenerating retinotectal projection in goldfish (Schmidt, 1988). It is therefore possible that the loss of selectivity we observe in kitten striate cortex after APV is a consequence of the destabilization of immature excitatory connections.

\section{Contribution of NMDA receptors to the mechanisms of visual cortical plasticity}

The notion that NMDA receptor activation is necessary for the consolidation and strengthening of developing synapses in striate cortex is supported by our finding that APV infusion blocks the 

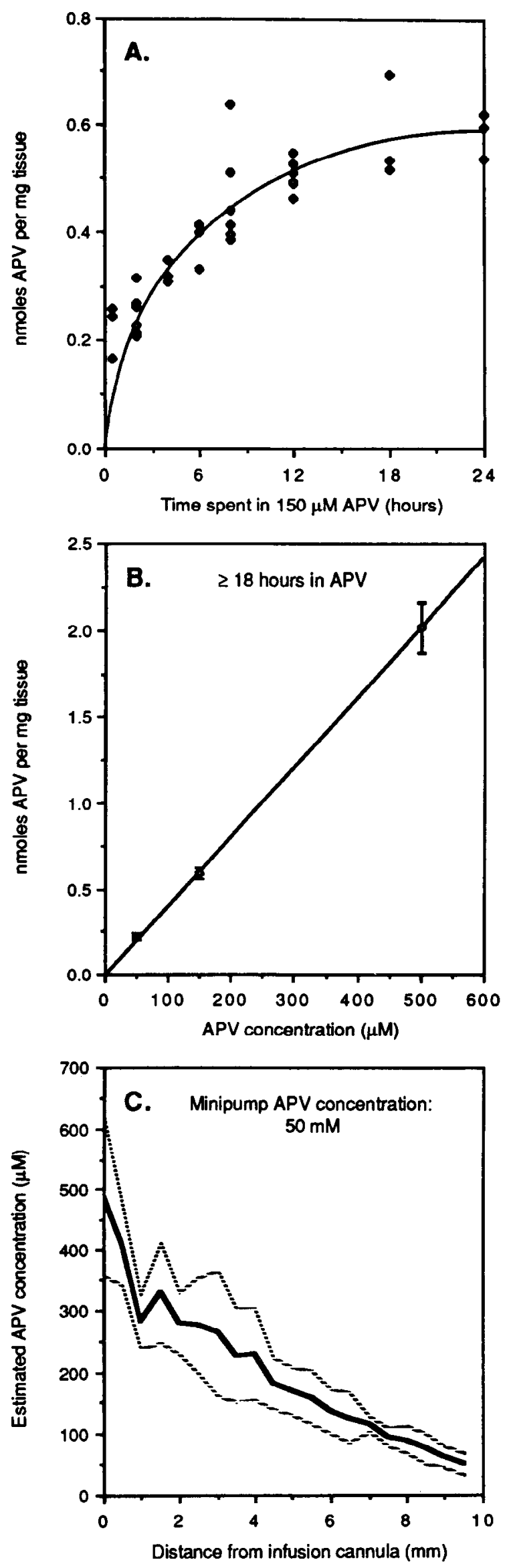

acquisition of selectivity and visual responsiveness that normally results from light exposure after a period of dark rearing (Fig. 8). Data from in vitro slice experiments also lend strong support to this hypothesis. Lasting increases in synaptic strength apparently cannot be induced by tetanic electrical stimulation in either the CA1 subfield of the hippocampus (Collingridge et al., 1983; Harris et al., 1984) or the visual cortex of rats (Artola and Singer, 1987; Kimura et al., 1988) and kittens (Connors and Bear, 1988) when NMDA receptors are blocked. On the other hand, the application of NMDA to hippocampal slices can induce a form of synaptic potentiation that can last for 30 min (Kauer et al., 1988) or longer (Thibault et al., 1989). The fact that one component of the inward current produced by NMDA is carried by $\mathrm{Ca}^{2+}$ has led to the hypothesis that the local postsynaptic elevation of $\left[\mathrm{Ca}^{2+}\right]$ triggers the biochemical changes that lead to increased synaptic effectiveness. In support of this hypothesis, intracellular injection of the calcium chelator EGTA blocks the induction of LTP in CA1 pyramidal cells (Lynch et al., 1983). Further, the intracellular release of $\mathrm{Ca}^{2+}$ from nitr-5 in CA 1 pyramidal cells produces a long-lasting potentiation of synaptic transmission that is indistinguishable from LTP (Malenka et al., 1988). Taken together, the data support the hypothesis that the calcium conductance mediated by the NMDA receptor plays a special role in strengthening synaptic relationships in the cortex. Because this conductance is voltagedependent, such a mechanism would fulfill the requirements of Hebb's famous postulate that synaptic strength increases when pre- and postsynaptic elements are concurrently active.

What are the mechanisms which support the weakening and elimination of synaptic inputs in the striate cortex? The dramatic differences in the rate of synaptic weakening observed after MD and $\mathrm{BD}$, for example, strongly suggest that sustained postsynaptic activation, perhaps above some threshold, normally promotes the rapid down-rcgulation of deprived inputs (Stent, 1973; Singer et al., 1977; Rauschecker and Singer, 1979; Bienenstock et al., 1982; Bear et al., 1987; Greuel et al., 1988). This mechanism has been termed "heterosynaptic depression," because the postsynaptic activity sustained by nondeprived afferents leads to the functional disconnection of deprived afferents. Although the precise nature of this voltage-dependent postsynaptic "punishment" signal is unknown, the present data suggest that it may also be sensitive to chronic NMDA receptor blockade.

A second mechanism of synaptic weakening is suggested by the observation of a "reverse" OD shift away from the more active eye when kittens are monocularly deprived as cortical neurons are inhibited with muscimol (Reiter and Stryker, 1988). Assuming that this effect is not due to a disruption of cortical metabolism, these data suggest that whether or not a given

Figure 14. A, Accumulation of APV by slices of striate cortex maintained in vitro at $37^{\circ} \mathrm{C}$ in continuously oxygenated artificial cerebrospinal fluid. Each point represents the measurement of APV content in an individual slicc. The accumulation appears to have become asymptotic by $18 \mathrm{hr}$ in $150 \mu \mathrm{M} \mathrm{APV}$, at which time the tissue concentration is 0.59 $\pm .03 \mathrm{nmol} / \mathrm{mg}$. $B$, The relationship between the concentration of APV in the bath and measured tissue concentration of APV (mean \pm SEM), measured after $\geq 18 \mathrm{hr}$ of incubation. $C$, The extracellular APV concentration at different distances from the infusion cannula, as calculated from the measured tissue APV content using the relationship derived in $B[\mu \mathrm{M} \mathrm{APV}=(\mathrm{nmol} \mathrm{APV} / \mathrm{mg}) \div 0.004]$. The infusion was at 50 $\mathrm{nmol} / \mathrm{hr}$ for $4 \mathrm{~d}$. The solid line represents the mean of 4 experiments; the dashed lines show $\pm 1 \mathrm{SD}$. 
pattern of input activity yields an increase or a decrease in synaptic strength depends critically on whether the target neuron is allowed to respond. Because the conductance of the NMDA receptor channel depends on the postsynaptic membrane potential, the NMDA receptor provides an ideal mechanism to perform this contingency matching operation. According to this line of reasoning, input activity leads to "homosynaptic depression" when the NMDA channel conductance falls below a certain threshold (Bear et al., 1987; Bear, 1988). Our finding of an OD bias away from the open eye in recordings near the APV infusion cannula (Fig. 11) is consistent with this hypothesis.

Together, these considerations lead us to the following interpretation of the effects of chronic APV infusion. We propose, first, that the partial suppression of postsynaptic activity by APV interferes with the voltage-dependent mechanism of heterosynaptic depression. This could account for the absence of an OD shift after MD during APV infusion. Second, we propose that APV infusion disrupts the ongoing processes of synaptic strengthening and consolidation. This could account for the loss of selectivity and response vigor, as well as for the ineffectiveness of monocular visual experience after dark rearing or RS, during APV infusion. Third, we propose that close to the infusion cannula, where NMDA receptors are rendered completely ineffective and postsynaptic activity is low, then presynaptic input activity alone produces a form of homosynaptic depression. This interpretation can account for the OD bias away from the more active eye in recordings near the APV cannula, as well as the effects of intracortical muscimol infusion (Reiter and Stryker, 1988).

The search for the molecular mechanisms of experience-dependent synaptic modifications in the visual cortex has narrowed considerably in the last 15 years (Stent, 1973; Singer, 1979, 1989; Bear, 1988). We now have theoretical (Bear et al., 1987) and experimental (Artola and Singer, 1987; Kleinschmidt et al., 1987; Kimura et al., 1988; Gu et al., 1989; present results) support for the hypothesis that NMDA receptors play a direct role in the consolidation of at least some excitatory synaptic relationships during postnatal cortical development, and possibly an indirect role in the mechanisms subserving synaptic elimination. As more is learned about the specific mechanisms of synaptic excitation and inhibition in the developing striatc cortex, it should be possible to refine these working hypotheses further.

\section{References}

Andersen, P. O. (1987) Long-term potentiation: Outstanding problems. In The Neural and Molecular Bases of Learning. I.-P. Changeux and M. Konishi, eds., pp 239-262, Wiley, New York.

Artola, A., and W. Singer (1987) Long-term potentiation and NMDA receptors in rat visual cortex. Nature 330: 649-652.

Bear, M. F. (1988) Involvement of excitatory amino acid receptors in the experience-dependent development of visual cortex. In Recent Advances in Excitatory Amino Acid Research, E. A. Cavalheiro, J. Lehman, and L. Turski, eds., Liss, New York.

Bear, M. F., and W. Singer (1986) Modulation of visual cortical plasticity by acetylcholine and noradrenaline. Nature 320: 172-176.

Bear, M. F., L. N. Cooper, and F. F. Ebner (1987) A physiological basis for a theory of synapse modification. Science 237: 42-48.

Berry, R. L., T. J. Teyler, and H. Taizhen (1988) Induction of LTP in rat primary visual cortex: Tetanus parameters. Brain Res. (in press).

Bienenstock, E. L., L. N. Cooper, and P. W. Munro (1982) Theory for the development of neuron selectivity: Orientation specificity and binocular interaction in visual cortex. J. Neurosci. 2: 32-48.

Blakemore, C., and R. C. Van Sluyters (1974) Reversal of the phys- iological effects of monocular deprivation in kittens: Further evidence for a sensitive period. J. Physiol. (Lond.) 237: 195-216.

Bliss, T. V. P, and T. Lømo (1973) Long-lasting potentiation of synaptic transmission in the dentate area of the anaesthetized rabbit following stimulation of the perforant path. J. Physiol. (Lond.) 232: 331-356.

Bradford, M. M. (1976) A rapid and sensitive method for the quantitation of microgram quantities of protein utilizing the principle of protein dye binding. Anal. Biochem. 72: 248-254.

Brown, T. H., A. H. Ganong, E. W. Kairiss, and C. L. Keenan (1989) Hebbian synapses: Biophysical mechanisms and algorithms. Annu. Rev. Neurosci. 12 (in press).

Cline, H. T., E. A. Debski, and M. Constantine-Paton (1987) $\mathrm{N}$-methyl-D-aspartate receptor antagonist desegregates eye-specific stripes. Proc. Natl. Acad. Sci. USA 84: 4342-4345.

Collingridge, G. I., S. I. Kehl, and H. McI ennan (1983) Excitatory amino acids in synaptic transmission in the Schaffer collateral-commisural pathway of the rat hippocampus. J. Physiol. (Lond.) 334: 3346.

Connors, B. W., and M. F. Bear (1988) Pharmacological modulation of long term potentiation in slices of visual cortex. Soc. Neurosci. Abstr. 14: 298.8.

Cooper, L. N. (1973) A possible organization of animal memory and learning. In Proceedings of the Nobel Symposium on Collective Properties of Physical Systems, Vol. 24, B. Lindquist and S. Lindquist, eds., pp. 252-264, Academic, New York.

Dingledine, R. (1983) N-methylaspartate activates voltage-dependent calcium conductance in rat hippocampal pyramidal cells. J. Physiol. (Lond.) 343: 385-405.

Foster, A. C., and G. E. Fagg (1985) Amino acid binding sites in mammalian neuronal membranes: Their characteristics and relationship to synaptic receptors. Brain Res. Rev. 7: 103-164.

Fox, K., H. Sato, and N. W. Daw (1989) The location and function of NMDA receptors in cat and kitten visual cortex. J. Neurosci. 9: 2443-2454.

Freeman, R. D., R. Mallach, and S. Hartley (1981) Responsivity of normal kitten striate cortex deteriorates after brief binocular deprivation. J. Neurophysiol. 45: 1074-1084.

Frègnac, Y., and M. Imbert (1984) Development of neuronal selectivity in the primary visual cortex of the cat. Physiol. Rev. 64: 325434.

Frégnac, Y., D. Shulz, S. Thorpe, and E. Bienenstock (1988) A cellular analogue of visual cortical plasticity. Nature $333: 367-370$.

Greuel, J. M., H. J. Luhman, and W. Singer (1987) Evidence for a threshold in experience-dependent long-term changes of kitten visual cortex. Dev. Brain Res. 34: 141-149.

Greuel, J. M., H. J. Luhman, and W. Singer (1988) Persistent changes of single-cell responses in kitten striate cortex produced by pairing sensory stimulation with iontophoretic application of neurotransmitters and neuromodulators. In Cellular Mechanisms of Conditioning and Behavioral Plasticity, C. D. Woody, D. L. Alkon, and J. L. McGaugh, eds., pp. 425-436, Plenum, New York.

Gu, Q., M. F. Bear, and W. Singer (1989) Blockade of NMDA-receptors prevents ocularity changes in kitten visual cortex after reversed monocular deprivation. Dev. Brain Res. 47: 281-288.

Harris, E. W., A. H. Ganong, and C. W. Cotman (1984) Long-term potentiation involves activation of $\mathrm{N}$-methyl $\mathrm{D}$-aspartate receptors. Brain Res. 323: 132-137.

Haycock, D. A., and M. F. Bear (1984) Stability of 6-hydroxydopamine under minipump conditions. Exp. Brain Res. 56: 183-186.

Hebb, D. O. (1949) The Organization of Behavior, Wiley, New York.

Hubel, D. H., and T. N. Wiesel (1970) The period of susceptibility to the physiological effects of unilateral eye closure in kittens. J. Physiol. (Lond.) 206: 419-436.

Kasamatsu, T., T. Itakura, and G. Jonsson (1981) Intracortical spread of exogenous catecholamines: Effective concentration for modifying cortical plasticity. J. Pharmacol. Exp. Ther. 217: 841-850.

Kauer, J. A., R. C. Malenka, and R. A. Nicoll (1988) NMDA application potentiates synaptic transmission in the hippocampus. Nature 334: $250-252$.

Kelso, S. R., A. H. Ganong, and T. H. Brown (1986) Hebbian synapses in hippocampus. Proc. Natl. Acad. Sci. USA 83: 5326-5330.

Kimura, F., T. Tsumoto, A. Nishigori, and T. Shirokawa (1988) Longterm synaptic potentiation and NMDA receptors in the rat pup visual cortex. Soc. Neurosci. Abstr. 14: 81.10. 
Kleinschmidt, A., M. F. Bear, and W. Singer (1987) Blockade of "NMDA" receptors disrupts experience-dependent modifications of kitten striate cortex. Science 238: 355-358.

Komatsu, V. K. Fujii, Jun Maeda, H. Sakaguchi, and K. Toyama (1988) Long-term potentiation of synaptic transmission in kitten visual cortex. J. Neurophysiol. (in press).

Linsker, R. (1986) From basic network principles to neural architectures: Emergence of orientation selective cells. Proc. Natl. Acad. Sci. USA 83: 8390-8394.

Lynch, G., and M. Baudry (1984) The biochemistry of memory: A new and specific hypothesis. Science 224: 1057-1063.

Lynch, G., J. Larson, S. Kelso, S. Barrionuevo, and F. Schottler (1983) Intracellular injections of EGTA block induction of hippocampal longterm potentiation. Nature 305: 719-721.

MacDermott, A. B., M. L. Mayer, G. L. Westbrook, S. J. Smith, and J. L. Barker (1986) NMDA receptor activation increases cytoplasmic calcium concentration in cultured spinal cord neurones. Nature 321: 519-522.

Malenka, R. C., J. A. Kauer, R. S. Zucker, and R. A. Nicoll (1988) Postsynaptic calcium is sufficient for potentiation of hippocampal synaptic transmission. Science 242: 81-84.

Mayer, M. L., and G. L. Westbrook (1987) The physiology of excitatory amino acids in the vertebrate central nervous system. Prog. Neurobiol. 28: 197-276.

McNaughton, B. L., R. M. Douglas, and G. V. Goddard (1978) Synaptic enhancement in fascia dentata: Cooperativity among coactive afferents. Brain Res. 157: 277-293.

Miller, K. D., B. Chapman, and M. P. Stryker (1989) Visual responses in adult visual cortex depend on $\mathrm{N}$-methyl-D-aspartate receptors. Proc. Natl. Acad. Sci. USA 86: 5183-5187.

Nowak, L., P. Bregostovski, P. Ascher, A. Herbert, and A. Prochiantz (1984) Magnesium gates glutamate-activated channels in mouse central neurones. Nature 307: 462-465.

Paradiso, M. A., M. F. Bear, and J. D. Daniels (1983) The effects of intracortical 6-hydroxydopamine on the response of kitten visual cortex to monocular deprivation. Exp. Brain Res. 51: 413-422.

Perkins, A. T., and T. J. Teyler (1988) A critical period for long term potentiation in the developing rat visual cortex. Brain Res. 439: 222229.

Ramoa, A. S., M. A. Paradiso, and R. D. Freeman (1989) Blockade of intracortical inhibition in kitten striate cortex: Effects on receptive field properties and associated loss of ocular dominance plasticity. Exp. Brain Res. 73: 285-296.

Rauschecker, J. P., and W. Singer (1979) Changes in the circuitry of the kitten's visual cortex are gated by postsynaptic activity. Nature 280: 58-60.

Rauschecker, J., and W. Singer (1982) Binocular deprivation can erase the effects of preceding monocular or binocular vision in kitten cortex. Dev. Brain Res. 4: 495-498.

Reiter, H.O., and M. P. Stryker (1988) Neural plasticity without action potentials: Less active inputs become dominant when kitten visual cortical cells are pharmacologically inhibited. Proc. Natl. Acad. Sci. USA 85: 3623-3627.

Reiter, H. O., D. M. Waitzman, and M. P. Stryker (1986) Cortical activity blockade prevents ocular dominance plasticity in the kitten visual cortex. Exp. Brain Res. 65: 182-188.

Scherer, W. S., and S. B. Udin (1988) The role of NMDA receptors in the development of binocular maps in Xenopus tectum. Soc. Neurosci. Abstr. 14: 272.16.

Schmidt, J. T. (1988) NMDA blockers prevent both retinotopic sharpening and LTP in regenerating optic pathway of goldfish. Soc. Neurosci. Abstr. 14: 272.15.

Shaw, C., and M. Cynader (1984) Disruption of cortical activity prevents ocular dominance changes in monocularly deprived kittens. Nature 308: 731-734.

Sherman, S. M., and P. D. Spear (1982) Organization of visual pathways in normal and visually deprived cats. Physiol. Rev. 62: 738855.

Singer, W. (1979) Central core control of visual cortex functions. In The Neurosciences Fourth Study Program, F. O. Schmitt and F. G. Worden, eds., pp. 1093-1109, MIT Press, Cambridge, MA.

Singer, W. (1987) Activity-dependent self-organization of synaptic connections as a substrate of lcarning. In The Neural and Molecular Bases of Learning, J.-P. Changeux and M. Konishi, eds., pp. 301336., Wiley, New York.

Singer, W. (1989) Ontogenetic self-organization and learning. In Brain Organization and Memory: Cells, Systems and Circuits, J. L. McGaugh, N. M. Weinberger, and G. Lynch, eds., Oxford U. P., New York (in press).

Singer, W., J. Rauschecker, and R. Werth (1977) The effect of monocular exposure to temporal contrasts on ocular dominance in kittens. Brain Res. 134: 568-572.

Stent, G. S. (1973) A physiological mechanism for Hebb's postulate of learning. Proc. Natl. Acad. Sci. USA 70: 997-1001.

Stryker, M. P., and W. A. Harris (1986) Binocular impulse blockade prevents the formation of ocular dominance columns in cat visual cortex. J. Neurosci. 6: 2117-2133.

Thibault, O., M. Joly, D. Müller, F. Schottler, S. Dudek, and G. Lynch (1989) Long-lasting physiological effects of bath applied N-methylD-aspartate. Brain Res. 476: 170-173.

Tsumoto, T., H. Masui, and H. Sato (1986) Excitatory amino acid neurotransmitters in neuronal circuits of the cat visual cortex. J. Neurophysiol. 55: 469-483.

Tsumoto, T., H. Hagihara, H. Sato, and Y. Hata (1987) NMDA receptors in the visual cortex of young kittens are more effective than those of adult cats. Nature 327: 513-514.

von der Marlsburg, C. (1973) Self-organization of orientation sensitive cells in the striate cortex. Kybernetik 14:85-100.

Watkins, J. C., and R. H. Evans (1981) Excitatory amino acid transmitters. Annu. Rev. Pharmacol. Toxicol. 21: 165-204.

Wicscl, T. N., and D. H. Hubcl (1965) Comparison of the effects of unilateral and bilateral eye closure on cortical unit responses in kittens. J. Neurophysiol. 28: 1029-1040.

Wigström, H., and B. Gustafsson (1985) On long-lasting potentiation in the hippocampus: A proposed mechanism for its dependence on coincident pre- and post-synaptic activity. Acta Physiol. Scand. 123: 519-522. 